\title{
Crises de Segurança do Alimento e a Demanda por Carnes no Brasil ${ }^{1,2}$
}

\author{
Moisés de Andrade Resende Filho ${ }^{3}$, Karina Junqueira de Souza ${ }^{4}$ e \\ Luís Cristóvão Ferreira Lima
}

Resumo: Investiga-se se crises de segurança do alimento deslocam para baixo as demandas por carne bovina, suína e de frango no Brasil. Constroem-se três séries de índices de crises de segurança do alimento, um para cada tipo de carne, somando-se o total de notícias na Folha de São Paulo que atenderam a critérios predefinidos de busca. Utilizam-se estas três séries, os preços das carnes e de um bem composto e o gasto per capita com consumo como variáveis explicativas em seis especificações alternativas de um sistema de quatro equações de demanda. Seleciona-se a melhor especificação do modelo por meio de testes ajustados de razão de verossimilhança. Testes com o modelo selecionado não rejeitam a hipótese de que as demandas não são afetadas por crises de segurança do alimento. Conclui-se que se deslocamentos da demanda para baixo em reação a crises de segurança do alimento criam incentivos para que as empresas adotem medidas para produzir um alimento mais seguro, tais incentivos não existem nos setores de carnes no Brasil. Assim, reforça-se a importância e necessidade de um sistema público ativo para regulamentar e estabelecer padrões de segurança da carne no Brasil.

Palavras-chaves: Segurança do alimento; Sistemas de equações de demanda; Setor de carnes; Brasil.

Abstract: We investigate whether food safety crises affect the demands for beef, pork and chicken in Brazil. We construct series of food safety crisis indices for each meat (beef, pork and chicken) based on the total number of news in 'Folha de São Paulo' newspaper fitting predefined search criteria. We use those series, the retail prices of each type of meat, the price of a composite good and per capita expenditure on consumption as explanatory variables

1. Os autores agradecem o financiamento da UnB, CNPq e Fapemig para elaboração deste trabalho. $\mathrm{O}$ primeiro autor agradece ao $\mathrm{CNPq}$ a bolsa de produtividade $2 \mathrm{em}$ pesquisa.

2. Data de submissão: 8 de julho de 2015. Data de aceite: 10 de maio de 2016.

3. Universidade de Brasília, Brasília, DF, Brasil. E-mail: moisesresende@unb.br

4. Hospital Universitário de Brasília, Universidade de Brasília, Brasília, DF, Brasil. E-mail: souzakarina@hotmail.com

5. Travix International B.V., Amsterdam, Noord-Holland, The Netherlands. E-mail: tovaodf@hotmail.com 
in six specifications of a four-equation demand system. We select the preferred specification of the models based on adjusted likelihood ratio tests. Based on the preferred model specification we do not reject the hypothesis by which food safety crisis do not affect the demand for meat in Brazil. We conclude that if the shifts down in the demand in response to food safety crises create incentives for companies to adopt measures to produce safer food, such incentives do not exist in the meat sector in Brazil. This reinforces the importance and necessity of an active public system to regulate and establish standards for meat safety in Brazil.

Key-words: food safety, system of demand equations, meat industry, Brazil.

DOI - http://dx.doi.org/10.1590/1234-56781806-94790540304 ～Classificação JEL: C32, Q11, Q13, Q18.

\section{Introdução}

Questões relacionadas a crises de segurança do alimento ${ }^{6}$ vêm ocupando a mídia com episódios de surtos de zoonoses (BSE, gripe aviária, tuberculose bovina), de doenças transmitidas por alimentos (DTA $)^{7}$ devido à contaminação com salmonella, listeria, Escherichia coli (E. coli) e trichinae, staphylococcus e uso ilegal ou excessivo de hormônios e antibióticos na produção de frango, bovinos e suínos. Por exemplo, nos EUA foi amplamente noticiada a detecção e o recall de hambúrgueres contaminados com E. coli ${ }^{8}$ e o recall de produtos com carne de frango e de peru contaminadas

6. Diz-se que o alimento é seguro se este está livre de contaminação biológica, de toxinas pré-formadas devido à proliferação de patógenos toxigênicos, de contaminação química (agrotóxicos, produtos químicos e metais pesados) e de contaminação física (pedaços de objetos e embalagem) em quantidade insuficiente para afetar a saúde do consumidor.

7. Doenças transmitidas por alimentos (DTA) é uma expressão genérica para designar toda síndrome geralmente constituída de anorexia, náuseas, vômitos e/ou diarréia decorrente da ingestão de alimentos ou água contaminados com células vegetativas viáveis de um agente infeccioso específico ou com toxinas pré-formadas resultantes da proliferação de patógenos toxigênicos, substancias químicas ou que contenham em sua constituição estruturas naturalmente tóxicas (TAVARES e SERAFINI, 2006; BOLETIM ELETRÔNICO EPIDEMIOLÓGICO, 2005).

8. Infecções causadas pela bacteria E. coli O157:H7 podem levar à Síndrome Hemolítica Urêmica (SHU), caracterizada por destruição das células vermelhas do sangue e falência renal que podem ser acompanhadas de deterioração neurológica e insuficiência renal crônica. com Listeria monocytogene 9 em 2002 e foram oficialmente confirmados no Canadá e EUA os primeiros casos de animais detectados com o mal da vaca louca ou BSE (Bovine Spongiform Encephalopathy) em 2003. Na Europa, há notícias de casos envolvendo a contaminação da carne de frango, leite e derivados com dioxina ${ }^{10}$ na Bélgica, de uso ilegal ou em doses excessivas de hormônios de crescimento e antibióticos na produção de frango, bovinos e suínos (MARUCHECK et al., 2011). No Brasil, há vários casos noticiados envolvendo surtos de peste suína nos rebanhos brasileiros, carne bovina importada contaminada com radiação, gripe aviária em 2006 e gripe suína em 2009.

Todo alimento possui atributos de bem privado, pois o consumidor, ao ingerir uma unidade de alimento, recebe todo o benefício deste e, ao mesmo tempo, elimina a possibilidade de alguém mais consumi-la. No entanto, cada unidade de alimento pode apresentar perigo à saúde humana se trouxer consigo patógenos (conta-

9. Infecções causadas pela bactéria Listeria monocytogene causam a listeriose que, se atinge o sistema nervoso, pode levar a sintomas como dor de cabeça, torcicolo, confusão mental, perda de equilíbrio e convulsões. Infecções durante a gravidez podem causar aborto, parto prematuro e infecções no recém-nascido. Adultos com o sistema imunológico em perfeito funcionamento podem apresentar gastroenterite febril aguda.

10. Entre os males causados pela dioxina no ser humano está o extermínio das defesas orgânicas (comparado à Aids), o surgimento de vários tipos de cânceres e a teratogenia, isto é, a geração de crianças deformadas. 
minação biológica) e/ou toxinas pré-formadas devido à proliferação de patógenos toxigênicos, metais pesados e resíduos químicos (contaminação química) e/ou partes de objetos e embalagens (contaminação física) (HENSON e TRAIL, 1993). Assim, uma unidade de alimento, se estiver contaminada em um nível suficientemente elevado para causar dano à saúde humana, também passa a apresentar atributos de mal público. Isso porque toda vez que há algum surto de DTA, os custos advindos da perda de bem-estar devido à condição de doença, da redução da produtividade e da força de trabalho, no caso de haver mortes, e dos procedimentos necessários ao restabelecimento da saúde do indivíduo não são, normalmente, pagos por quem produziu a unidade de alimento imprópria ao consumo humano. Em última instância, é o próprio consumidor e os demais contribuintes que arcam com estes custos via sistema público de saúde e de seguridade social. Em outras palavras, a possibilidade de surtos por DTA (uma potencial externalidade negativa do consumo de alimentos) traz consigo a possibilidade de falha no mercado de qualquer alimento.

Dados do Sistema Nacional de Vigilância Epidemiológica das Doenças Transmitidas por Alimentos (VE-DTA) ${ }^{11}$ indicam que ocorreram 9.942 surtos de DTA (710,15 surtos ao ano), muitos dos quais foram amplamente noticiados, 148.433 internações por DTA (10.602 internações por DTA ao ano) no período 2000 a 2014 no Brasil (ALVES, 2014). A carne bovina in natura, processados e miúdos responderam por 3,7\% do total de surtos no período, a carne suína in natura, processados e miúdos, por $2,20 \%$, e a carne de ave in natura, processados e miúdos, por 2,4\%. Em 51,24\% dos surtos não foi possível identificar o agente etioló-

11. O VE-DTA foi desenvolvido pela Secretaria de Vigilância em Saúde (SVE) do Ministério da Saúde com o objetivo de reduzir a incidência das DTA no Brasil. O VE-DTA entrou em operação em 1999 em parceria com a Agência Nacional de Vigilância Sanitária (Anvisa), Ministério da Agricultura, Pecuária e Abastecimento (Mapa) e Instituto Pan-Americano de Alimentos da Organização Pan-Americana de Saúde (OPAS). O VE-DTA utiliza o Sistema de Informação de Agravos de Notificação (Sinan), que permite detectar a ocorrência de um evento suspeito na população e indicar perigos aos quais está sujeita (ALVES, 2014). gico, mas a Salmonella spp e E. coli foram identificadas como o agente etiológico em 18,09\% e 6,33\% dos surtos (ALVES, 2014). Ademais, é provável que os dados do VE-DTA subestimem os reais casos de DTA no Brasil devido à subnotificação.

Admite-se que os consumidores criam incentivos para que as empresas adotem medidas para produzir um alimento mais seguro, se alteram suas escolhas em reação a crises de segurança do alimento, deslocando assim para baixo a demanda de mercado, conforme modelo conceitual na seção dois do presente artigo. Com isso, a adoção de medidas pelas empresas em antecipação à reação dos consumidores a crises de segurança do alimento atenua, podendo até resolver, a falha de mercado e, assim, pode substituir e/ ou complementar as ações e instrumentos dos órgãos reguladores, Ministério da Agricultura (Mapa), Agência Nacional de Vigilância Sanitária (Anvisa) e Vigilâncias Sanitárias estaduais e municipais.

O objetivo do presente artigo é investigar se os consumidores das carnes bovina, suína e de frango no Brasil reagem a crises de segurança do alimento. Para atingir tal objetivo, estimaram-se seis especificações alternativas de um sistema de quatro equações de demanda para as principais carnes (bovina, suína e de frango) consumidas no mercado brasileiro e um bem composto, ainda incorporando índices que captam crises de segurança do alimento associadas a cada tipo de carne e que tenham sido veiculados em forma de notícias. As seis especificações alternativas estimadas do sistema de quatro equações de demanda por carnes no Brasil são o resultado da combinação de três formas de corrigir a autocorrelação dos erros com a inclusão e não inclusão das séries de índices agregados de segurança do alimento. Em seguida, efetuam-se testes estatísticos para selecionar a melhor especificação do modelo dentre as seis especificações estimadas, o que também envolve testar se crises de segurança do alimento afetam as demandas por carnes no Brasil no período de 1975 a 2011. Por fim, utilizam-se as estimativas do modelo selecionado para estimar elasticidades atualizadas das demandas por carne 
bovina, suína e de frango no Brasil, utilizando tais estimativas como mais um teste da robustez dos resultados obtidos.

O presente artigo possui sete seções, além dessa seção introdutória. A segunda e terceira seções apresentam o modelo conceitual e uma revisão da literatura recente acerca da detecção de efeitos de crises de segurança do alimento sobre a demanda por alimentos. A quarta seção descreve os dados e os procedimentos utilizados para obtenção das séries de índices de segurança do alimento. A quinta seção apresenta as etapas seguidas na especificação dos modelos econométricos e os testes utilizados na escolha do melhor modelo. A sexta seção apresenta e analisa os resultados do sistema escolhido dentre as seis especificações utilizadas para os sistemas de equações de demanda e as estimativas das elasticidades obtidas a partir dele. A sétima e última seção traz o sumário dos resultados obtidos ao longo do trabalho e uma discussão das implicações destes para a formulação de políticas públicas.

\section{Modelo conceitual}

A Figura 1 será utilizada para auxiliar a descrever como o deslocamento para baixo da curva de demanda de mercado em reação a uma crise de segurança do alimento pode gerar incentivos para que empresas do setor, no melhor dos seus próprios interesses, adotem medidas para reduzir o risco de futuras crises de segurança do alimento, mitigando, assim, uma falha de mercado.

No ponto $\mathrm{M}^{\prime}$ da Figura 1 ocorre a interseção da oferta ou Custo Marginal Privado (CMP') do setor e a demanda ou Benefício Marginal Privado $\left(\mathrm{BMP}^{\prime}\right)$ do setor e, portanto, ocorre o equilíbrio competitivo inicial de mercado. No entanto, a coordenada no eixo das quantidades do ponto $E^{\prime}$, resultante da interseção do Custo Marginal Social $\left(\mathrm{CMS}^{\prime}\right)$ e demanda do setor (BMP'), é que constitui a quantidade Pareto eficiente de alimento. Isso porque a curva CMS' é a soma do Custo Marginal Privado $\left(\mathrm{CMP}^{\prime}\right)$ e de um Valor Esperado

Figura 1. Caracterização de um mercado competitivo de alimento em presença de externalidades negativas geradas por crises de segurança do alimento

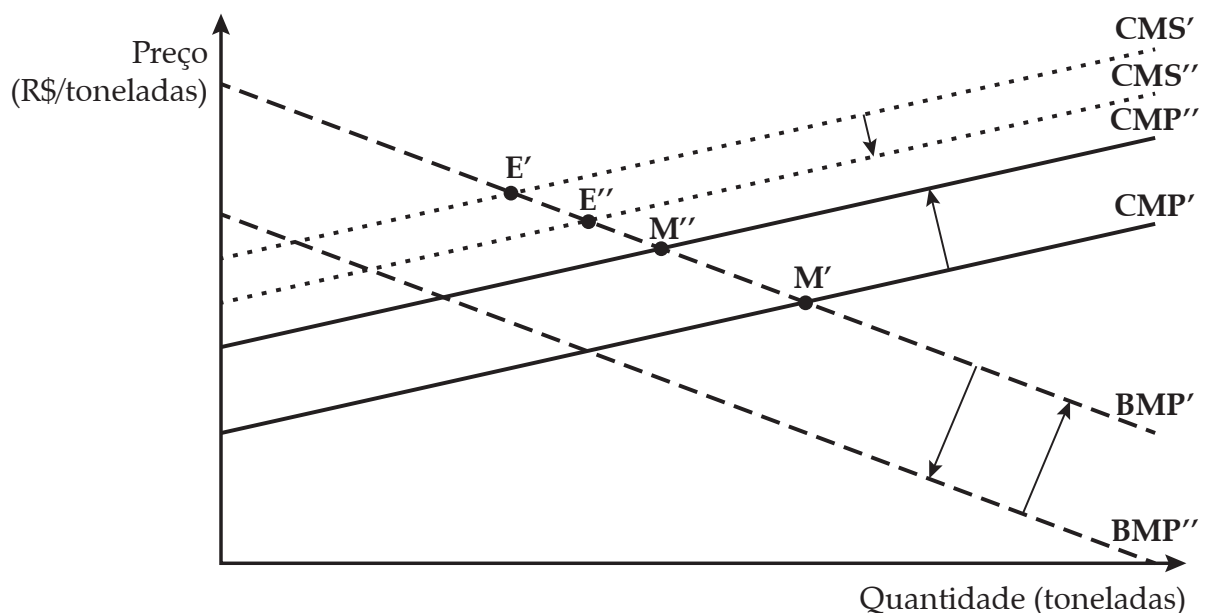

Fonte: Elaboração própria. 
do Custo Marginal Externo (VECME) constante ${ }^{12}$. Assim, comparando-se as coordenadas no eixo das quantidades dos pontos $\mathrm{M}^{\prime}$ e $\mathrm{E}^{\prime}$, observa-se que, no equilíbrio de mercado, a quantidade é maior que o nível Pareto eficiente, o que caracteriza uma falha de mercado.

Se os consumidores, no entanto, reagem às crises de segurança do alimento, modificando as suas escolhas ao ponto de promoverem o deslocamento da demanda de mercado de $\mathrm{BMP}^{\prime}$ para $\mathrm{BMP}^{\prime \prime}$, induzem assim à queda imediata do preço do produto (vide Figura 1), e, consequentemente, geram prejuízos de curto prazo para as empresas pré-existentes ${ }^{13}$ no setor. Assim, de modo a evitarem novos prejuízos com crises futuras de segurança do alimento, algumas empresas passam a adotar medidas para reduzirem o risco de futuras crises no setor, o que leva ao aumento do custo marginal de produção destas empresas e, consequentemente, promovem o deslocamento definitivo da oferta do setor de $\mathrm{CMP}^{\prime}$ para se tornar $\mathrm{CMP}^{\prime \prime}$. Ademais, admitindo-se que as medidas

12. Scharff (2011) estima que, nos EUA, o custo médio com cuidados médicos, perda de produtividade, mortalidade e perdas de bem-estar devido a uma condição de doença seja US\$ 1.626 (R\$ 4.878) por caso de doença transmitida por alimentos (DTA). Ainda para os EUA, Ross e Sumner (2002) estimam uma probabilidade de $6,2 \times 10^{-7}$ por 100 gramas de alimento de ocorrer um caso de DTA devido à contaminação pela bactéria $E$. coli. Com base nisso, obtém-se que o Valor Esperado dos Custos Externos (VECE) nos EUA é $\operatorname{VECE}(Q)=4878 \times 6,2 \times 10^{-3} \times Q$, em que $Q$ é a quantidade consumida de alimento em toneladas; e $6,2 \times 10^{-3} \times Q$ é o número esperado de casos de DTA. Com isso, estima-se um Valor Esperado do Custo Marginal Externo (VECME) constante e igual a R\$30,24, o que justifica na Figura $1 \mathrm{CMS}^{\prime}$ e CMS" paralelas ao Custo Marginal Privado ( $\left.\mathrm{CMP}^{\prime}\right)$.

13. Para simplificar a ideia, a Figura 1 retrata casos de crise de segurança do alimento sem efeito na oferta do setor. Como, por exemplo, o que aconteceu quando, em março de 1996, comprovou-se em laboratório a ligação entre a Encefalopatia Espongiforme Bovina ou mal da vaca louca e uma nova variante da doença Creutzfeldt-Jakob (vCJD) em humanos. Essa descoberta, apesar de ter criado pânico nos consumidores de carne bovina, não alterou imediatamente a quantidade ofertada de carne bovina porque a descoberta não tornou o produto impróprio para o consumo. Como um contraexemplo, Pouliot e Sumner (2013) desenvolvem um modelo em que um setor oligopolizado pode manipular a oferta de modo a lucrar mais por meio da determinação da probabilidade de crise de segurança do alimento do setor. adotadas pelas empresas reduzem realmente o risco de crises de segurança do alimento, tem-se em consequência a redução no Valor Esperado do Custo Marginal Externo (VECME), o que implica no descolamento definitivo de CMS' para CMS". Por fim, se os consumidores esquecem rapidamente as crises, como sugerem Piggott e Marsh (2004), a curva de demanda volta definitivamente a ser $\mathrm{BMP}^{\prime}$. Com isto, o novo equilíbrio de mercado de longo prazo passa a ser $\mathrm{M}^{\prime \prime}$ e a quantidade eficiente, aquela do ponto $\mathrm{E}^{\prime \prime}$, o que demonstra a atenuação da falha de mercado. Vale mencionar que se a redução no Valor Esperado do Custo Marginal Externo (VECME) for exatamente igual ao aumento no Custo Marginal Privado do setor, a falha de mercado é completamente equacionada. No entanto, essa possibilidade parece ser pouco provável.

Em suma, a reação dos consumidores às crises de segurança do alimento pode levar empresas, no melhor dos seus próprios interesses em evitar prejuízos futuros, a adotarem medidas que reduzem o risco de futuras crises de segurança do alimento, atenuando assim a falha de mercado sem qualquer intervenção externa.

\section{Revisão de literatura}

Há um grande número de trabalhos dedicados a detectar os impactos de crises de segurança do alimento na demanda por alimentos em outros países que não o Brasil.

No Reino Unido, Burton et al. (1999) estimaram uma versão estática modificada do modelo Almost Ideal Demand System (AIDS) para estudar o efeito de eventos noticiados na mídia sobre BSE sobre o consumo de carne bovina. Na Bélgica, Verbeke e Ward (2001) estimaram um sistema de equações de demanda do tipo AIDS, incorporando variáveis explicativas para o gasto com propaganda com a carne bovina/vitelo e carne suína/misturas e também uma variável para o número de notícias negativas veiculadas na mídia sobre estas mesmas carnes. Na Itália, Mazzocchi et al. (2004) utilizaram um modelo de equações 
de demanda dinâmico do tipo AIDS para estimar a redução no bem-estar do consumidor devido à não divulgação da informação de que poderia haver uma ligação entre o consumo de carne bovina e a doença Creutzfeldt-Jakob (vCJD) em humanos.

Os estudos para os EUA são os de maior número. Carter e Smith (2007) desenvolveram um método econométrico capaz de detectar e mensurar o impacto da contaminação da produção de milho americano com uma variedade geneticamente modificada chamada Starlink sobre o preço do milho nos EUA. Resende Filho e Buhr (2011) e Piggott e Marsh (2004) estimaram sistemas de equações de demanda e detectaram o efeito negativo de notícias envolvendo surtos de zoonoses (gripe suína e mal da vaca louca), enfermidades ou doenças transmitidas por alimentos contaminados com Salmonela, Listeria, E. coli, Trichinae e Staphylococcus e casos de uso ilegal ou excessivo de hormônios e antibióticos na produção animal sobre a demanda de carnes. Tonsor et al. (2010) construíram um modelo Rotterdam com cinco equações, uma para cada demanda de carne (bovina, suína e de frango), uma para a demanda pelos demais alimentos e outra para os bens não alimentícios, com dados trimestrais de 1982 a 2007. Estes autores buscam detectar o efeito de dois fatores pouco explorados nesse tipo de estudo: o dinamismo das famílias (por exemplo, o hábito de comer fora e se a mulher trabalha fora) e as informações relacionadas aos efeitos de atributos dos alimentos sobre a saúde. Para tanto, constroem três índices, um para artigos científicos relacionando gordura, colesterol ou doenças no coração com a dieta do indivíduo (FCHA), outro índice para artigos científicos relacionando zinco, ferro ou proteína à melhor saúde (ZIP) e, por último, um índice com os recalls de carne (nAtk). Finalmente, observaram que as variáveis mais significativas para a demanda de carne são o próprio-preço, o índice FCHA e a proporção de pessoas que se alimentam fora de casa. Também Glynn e Olynk (2010), para analisar os impactos de informações sobre o tratamento dado aos animais sobre as demandas por suas carnes, cons- truíram um índice trimestral com as notícias relacionadas ao tema publicadas nos maiores jornais e revistas norte-americanas entre 1982 e 2008.

Na Holanda, Jonge et al. (2010) investigaram o nível de confiança dos consumidores holandeses em relação ao alimento que consomem, utilizando dados obtidos por meio de questionários aplicados pela internet a diferentes pessoas em cada ano do período de 2003 a 2006. Com base em um modelo em que a percepção do consumidor sobre o alimento era representada por uma variável dependente binária (recebe um se é otimista e zero, caso contrário), os autores constataram que incidentes anteriores reduzem, significativamente, a probabilidade de o consumidor estar otimista. Na segunda parte do trabalho, Jonge et al. (2010) analisam o efeito de notícias a respeito da segurança do alimento e do número de recalls reportados. Para tanto, utilizam quatro grandes jornais holandeses no período de novembro de 2003 até novembro de 2006, selecionando reportagens que incluíam palavras relacionadas a crises de segurança do alimento e setor alimentício.

Fica evidente pelos artigos supracitados que ainda é importante realizar trabalhos econométricos com dados agregados de consumo (TONSOR et al., 2010; GLYNN e OLYNK, 2010; RESENDE FILHO e BUHR, 2011; PIGGOTT e MARSH, 2004) e é fundamental incluir variáveis que capturem o nível de confiança dos consumidores com relação ao alimento que consomem em modelos de demanda por alimentos. Em especial, é importante incluir algum índice construído com base em notícias sobre crises de segurança do alimento (JONGE et al., 2010; GLYNN e OLYNK, 2010; RESENDE FILHO e BUHR, 2011; PIGGOTT e MARSH, 2004) ou a partir do número de recall de alimentos (TONSOR et al., 2010).

Trabalhos que se dedicam ao estudo da reação dos consumidores a crises de segurança do alimento no Brasil são escassos. Os poucos estudos disponíveis, como os de Spers (2003) e Fonseca (2004), se restringem a realizar pesquisas de opinião com amostras pequenas de consumidores. Mais recentemente, Behrens et al. (2010) avaliaram as atitudes dos consumidores com relação à 
segurança do alimento na cidade de São Paulo, utilizando grupo focal para uma amostra de 30 adultos responsáveis pela escolha e compra de alimentos em seus domicílios.

\section{Descrição das variáveis e dados}

Nesta seção, faz-se a descrição dos procedimentos utilizados na coleta e manipulação dos dados de modo a construir as variáveis utilizadas nos modelos para o período de 1975 a 2011.

\section{1. Índices de segurança do alimento}

Três séries de índices de segurança do alimento foram construídas, uma série para cada tipo de carne, seguindo o que fizeram Piggott e Marsh (2004) ${ }^{14}$. Utiliza-se o acervo on-line da Folha de São Paulo (2012) por ser, na época da pesquisa, o único acervo de jornal brasileiro de circulação nacional inteiramente e gratuitamente disponível na internet. As buscas foram realizadas de modo que os artigos sobre problemas e crises de segurança do alimento fossem, separadamente, contabilizados para cada tipo de carne.

As buscas foram efetuadas inserindo-se, individualmente, no campo "com todas as palavras" do formulário de consulta (vide Figura 2), cada uma das seguintes palavras-chave: segurança alimentar, contaminação, recall de produtos ou recall ou recolha de produtos, surto, Salmonella, Listeria, E. coli, triquinose, estafilococos ou staphylococcus e intoxicação alimentar. Essas palavras-chaves são as mesmas utilizadas por Piggott e Marsh (2004), mas traduzidas para o português com o uso da ferramenta Google Tradutor disponível em https:// translate.google.com/ e o sítio web www.wikipedia.org, sendo que os nomes científicos em latim não foram traduzidos (vide Tabela 1 para mais detalhes).

14. Segundo Piggott e Marsh (2004, p. 157), com base em um modelo teórico de escolha do consumidor, o uso de uma única medida de qualidade, por exemplo, um único índice de segurança geral das carnes, impõe restrições à capacidade de resposta do consumidor e as suas utilidades marginais.
Adicionalmente às palavras-chaves propostas por Piggott e Marsh (2004), foram utilizadas as palavras-chaves BSE ou Encefalopatia Espongiforme Bovina ou vaca louca ou febre aftosa, como proposto por Resende Filho (2008).

Em cada busca, de modo a separar os resultados por tipo de carne, inserimos no campo "com pelo menos uma das palavras" (vide Figura 2), separadamente, cada um dos três conjuntos de palavras: carne hambúrguer; porco presunto; frango. Por exemplo, em uma busca utiliza-se a palavra-chave "contaminação" no campo "com a frase exata", juntamente com as palavras "carne hambúrguer" no campo "com pelo menos uma das palavras". Os resultados eram agrupados e apresentados pela ferramenta de busca da Folha de São Paulo (2012) por mês do período de janeiro de 1975 a dezembro de 2011. Em seguida, somava-se ${ }^{15}$ o total de notícias ${ }^{16}$ da Folha de São Paulo que atendiam aos critérios da busca.

Foram ainda pesquisados, separadamente, os termos bactéria, moléstia, gripe suína e gripe aviária no campo "com a frase exata", inserindo-se no campo "com pelo menos uma das palavras" (vide Figura 2), separadamente, cada um dos três conjuntos de palavras: carne hambúrguer; porco presunto; frango. Cada pesquisa retornava, em média, 300 resultados, que eram avaliados individualmente de modo a atestar se a notícia realmente se enquadrava no tema pesquisado (a proporção média foi de uma notícia relevante para cada cinco notícias avaliadas). A pesquisa surto + carne não foi contabilizada, pois retornou mais de 6.000 resultados de notícias, sendo que pouquíssimas se relacionavam à segurança do alimento e, as que se relacionavam, já haviam sido contabilizados em buscas anteriores.

15. Adota-se o mesmo procedimento utilizado por Piggott e Marsh (2004), não se fazendo qualquer tipo de ponderação, pois qualquer ponderação realizada se basearia em critérios arbitrários.

16. O número de artigos, no caso da presente pesquisa, corresponde também ao número de páginas publicadas, pois cada artigo retornado nunca ultrapassou uma página de extensão. Além disso, não se observam notícias que abordavam as palavras-chaves em um contexto positivo. 
Tabela 1. Palavras-chaves utilizadas por Piggott e Marsh (2004) e suas correspondentes traduções para o português

\begin{tabular}{lll}
\hline \multicolumn{1}{c}{ Keyword } & \multicolumn{1}{c}{ Palavra-chave } & \multicolumn{1}{c}{ Fonte da tradução para o Português } \\
\hline Food safety & Segurança alimentar, segurança do alimento & Google tradutor, tradução livre \\
Contamination & Contaminação & Tradução livre \\
Product recall & Recall de produtos, recall, recolha de produtos & Google tradutor e Wikipedia \\
Outbreak & Surto & Google tradutor \\
Salmonella & Salmonella & \\
Listeria & Listeria & Palavras em latim não foram traduzidas \\
E. coli & E. coli & \\
Trichinae & Triquinose (doença causada pela trichinae) & Google tradutor \\
Staphylococcus & Staphylococcus, Estafilococos & Google tradutor e Wikipedia \\
Foodbone & Intoxicação alimentar, doença transmitida por alimento & Wikipedia, tradução livre \\
\hline
\end{tabular}

Fonte: Elaboração própria.

Figura 2. Tela de abertura da ferramenta de busca da Folha de São Paulo (2012)

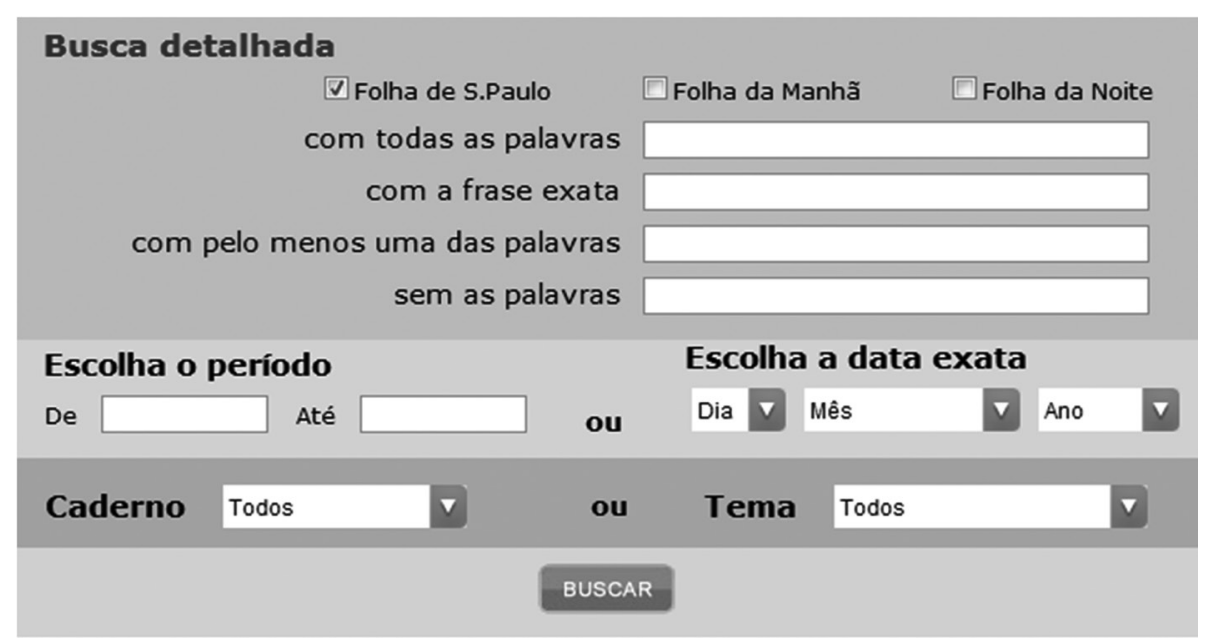

Fonte: Folha de São Paulo (2012).

Analisando-se as séries dos índices de segurança do alimento na Figura 3, as quais são a soma do número de notícias da Folha de São Paulo que atenderam aos critérios pré-definidos de busca, podem-se destacar seis grandes picos: o primeiro pico ocorre devido a notícias sobre um surto de peste suína nos rebanhos brasileiros entre junho e julho de 1978; o segundo, em 1988, decorre basicamente de um episódio de carne bovina importada contaminada com radiação; o terceiro pico, em 1996, está associado a seis notícias relacionadas às palavras-chaves surto, salmonella, zoonose e febre aftosa, mas foi fortemente determinado por quatro notícias sobre possíveis casos de vaca louca na Europa; o quarto pico, entre janeiro e março de 2003, está associado a notícias sobre o primeiro caso do mal da vaca louca no Canadá; o quinto pico, nos três primeiros meses de 2006, é devido a notícias sobre gripe aviária; finalmente, o sexto e último pico, entre julho e outubro de 2009 , se deve a notícias sobre gripe suína.

\subsection{Consumo aparente per capita}

As séries das quantidades consumidas das carnes bovina, suína e de frango são as mesmas reportadas pelo USDA/FAS (2012) e correspondem ao consumo aparente ao nível de varejo, calculado para cada ano segundo a identidade: consumo 
Figura 3. Séries anuais do número de notícias da Folha de São Paulo (2012) sobre crises de segurança do alimento relacionadas às carnes bovina, suína e de frango, tomando-se o período janeiro de 1975 a dezembro de 2011

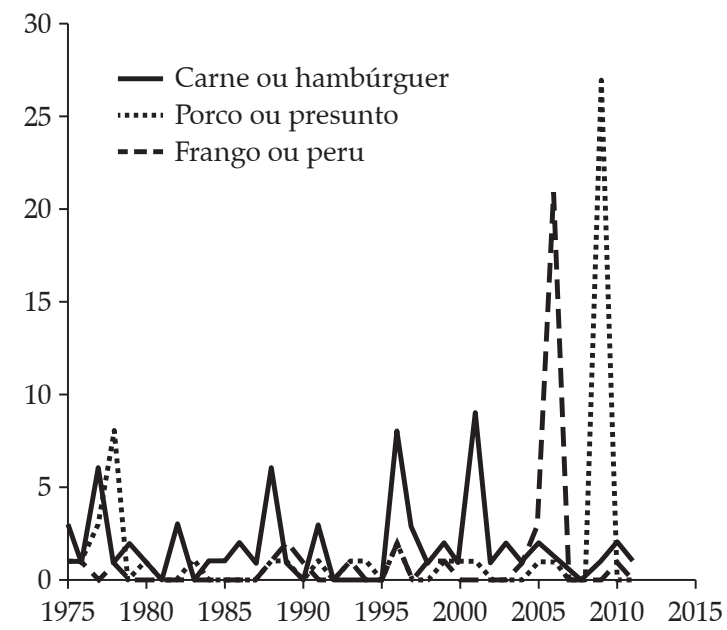

Fonte: Elaboração própria com base em Folha de São Paulo (2012).

Figura 4. Séries anuais do consumo aparente per capita no Brasil das carnes bovina, suína, de frango e total, de 1975 a 2011

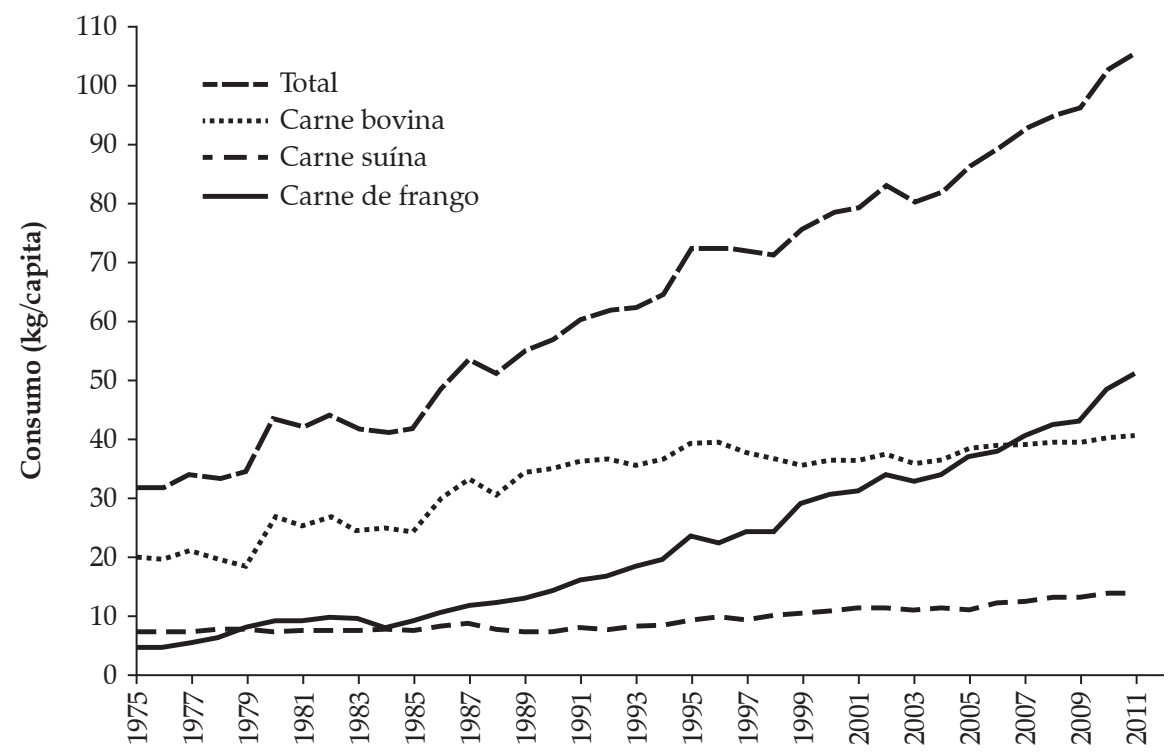

Fonte: Elaboração própria com base em dados de USDA/FAS (2012) e Ipea (2012). 
aparente da $i$-ésima carne $\equiv$ produção da carne $i+$ estoque inicial da carne $i+$ quantidade importada da carne $i$ - estoque final da carne $i$ - exportações da carne $i$. Em seguida, o consumo aparente por carne foi dividido pela população residente no Brasil em $1^{2}$ de julho de cada ano do IBGE e obtida no Ipea (2012), de modo a gerar as séries de consumo aparente per capita para cada tipo de carne de 1975 a 2011 no Brasil. Os gráficos destas séries são apresentados na Figura 4.

Pela Figura 4 é possível observar que as séries de consumo aparente per capita apresentam tendências diferentes, mas crescentes. Observa-se ainda que o consumo aparente de carne de frango ultrapassa o de carne suína a partir de 1979; e que o consumo aparente de carne de frango, 4,51 kg/pessoa em 1975, ou seja, mais que quatro vezes menor que o consumo de carne bovina, que era de 19,71 kg/pessoa, ultrapassa o consumo de carne bovina a partir de 2007. Um fenômeno similar ocorre nos EUA por volta de 1991 (SCHROEDER et al., 2000).

\subsection{Preços das carnes e gastos com outros bens de consumo}

As séries dos preços das carnes bovina, suína e de frango correspondem aos preços no varejo da cidade de São Paulo em R\$ por kg, obtidos do Instituto de Economia Aplicada de São Paulo (IEA, 2012). Estas séries foram utilizadas em razão da impossibilidade de se obter séries de preços em termos nacionais. Para deflacionar cada série de preço de modo a mensurá-las em valores constantes de R $\$$ de dezembro de 2011, utilizou-se a série do IGP-DI ${ }^{17}$ (Índice Geral de Preços

17. Qualquer índice de preços que fosse empregado traria consigo distorções, pois a inflação é sentida de forma diferente pelos consumidores e empresas. Assim, optou-se por homogeneizar o critério para deflacionar as séries, utilizando-se o IGP-DI. O IGP-DI (Índice Geral de Preços - Disponibilidade Interna) é um índice composto pelo IPA-DI (Índice de Preços por Atacado - Disponibilidade Interna), IPC-DI (Índice de Preços ao Consumidor Disponibilidade Interna) e INCC-DI (Índice Nacional do Custo da Construção - Disponibilidade Interna), com pesos de $60 \%$, 30\% e 10\%. Assim, o IGP-DI leva em conta a maioria dos itens que impactam a renda dos consumi-
- Disponibilidade Interna) da Fundação Getúlio Vargas, obtida no Ipea (2012). Os gráficos das séries de preços deflacionadas são apresentados na Figura 5.

Pela Figura 5 é possível observar uma tendência de declínio nos preços de cada carne e a aparente redução da volatilidade dos preços após 1994, ano em que o Plano Real se inicia.

Adotando o mesmo procedimento de Brester e Schroeder (1995), gerou-se a série de preços do bem composto, "outros bens de consumo", utilizando-se a série anual do IGP-DI da seguinte maneira. Primeiro, constrói-se a série gasto com todos os outros bens de consumo. Para tanto, subtrai-se a série gasto per capita com carnes da série gasto per capita com consumo. A série gasto per capita com consumo é computada a partir da divisão da série consumo das famílias, obtida no Ipea (2012), pela série da população residente no Brasil em 1o de julho de cada ano do IBGE, também obtida no Ipea (2012). Segundo, de posse das séries das parcelas do gasto com carne bovina, suína, de frango e outros bens de consumo, gera-se a série de preços deflacionados dos outros bens de consumo (série $p_{4} t$ ), resolvendo a igualdade IGP $-d i_{t}=\sum_{i=1}^{4} p_{i t} w_{i t}$ para $p_{4} t$, em que pit é o preço do $i$-ésimo bem no tempo $t$; e wit denota a parcela do gasto do $i$-ésimo bem no tempo $t$, calculado conforme está descrito abaixo da equação (1) a seguir.

As estatísticas descritivas das séries estão na Tabela 2.

Pelos dados apresentados na Tabela 2, percebe-se que, em média, o número de notícias da Folha de São Paulo sobre crises de segurança do alimento é pequeno, algo entre 1,865 notícia/ano para a carne bovina e 1,027 notícia/ano para a carne de frango.

dores, quais sejam: preços de legumes e frutas, bebidas e fumo, remédios, embalagens, aluguel, condomínio, empregada doméstica, transportes, educação, leitura e recreação, vestuário e despesas diversas (cartório, loteria, correio, mensalidade de Internet e cigarro, entre outros) e materiais de construção. 
Figura 5. Séries anuais dos preços das carnes bovina, suína e de frango no varejo da cidade de São Paulo, em $\mathrm{R} \$$ de dezembro de 2011 por $\mathrm{kg}$

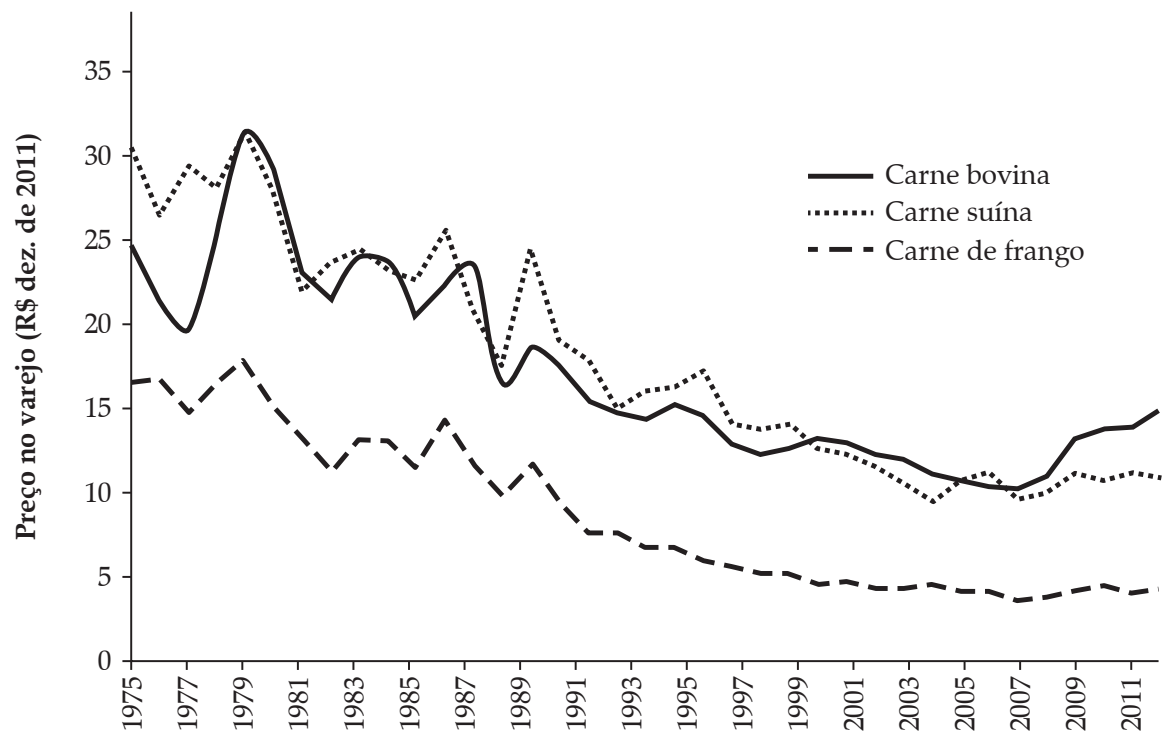

Fonte: Elaboração própria com base em dados de IEA (2012) e Ipea (2012).

Tabela 2. Estatísticas descritivas das séries anuais, de 1975 a 2011

\begin{tabular}{|c|c|c|c|c|}
\hline Variável & Média & $\begin{array}{l}\text { Desvio } \\
\text { Padrão } \\
\end{array}$ & Mínimo & Máximo \\
\hline Consumo de carne bovina (kg/pessoa) & 32,23 & 6,95 & 18,09 & 40,18 \\
\hline Consumo de carne suína (kg/pessoa) & 9,30 & 2,09 & 6713 & 13,74 \\
\hline Consumo de carne de frango (kg/pessoa) & 21,49 & 13,46 & 4,49 & 50,14 \\
\hline Preço da carne bovina no varejo $(\mathrm{R} \$ / \mathrm{kg})^{*}$ & 17,01 & 5,59 & 10,13 & 30,91 \\
\hline Preço da carne de frango no varejo $(\mathrm{R} \$ / \mathrm{kg})^{*}$ & 8,63 & 4,66 & 3,61 & 17,68 \\
\hline Preço da carne suína no varejo $(\mathrm{R} \$ / \mathrm{kg})^{*}$ & 17,80 & 6,86 & 9,46 & 31,14 \\
\hline Gasto com carnes (R $\$ /$ pessoa $)^{*}$ & 801,67 & 118,25 & 638,41 & $1.104,04$ \\
\hline Gasto com outros bens ( $\mathrm{R} \$ /$ pessoa $)^{*}$ & $11.243,07$ & $1.518,41$ & $8.661,69$ & $14.292,62$ \\
\hline Parcela do gasto com carne bovina & 0,043 & 0,01 & 0,03 & 0,06 \\
\hline Parcela do gasto com carne suína & 0,013 & 0,00 & 0,01 & 0,02 \\
\hline Parcela do gasto com carne de frango & 0,011 & 0,00 & 0,01 & 0,02 \\
\hline Parcela do gasto com outros bens & 0,933 & 0,01 & 0,90 & 0,95 \\
\hline Índice de segurança da carne bovina ( $\mathrm{n}^{\mathrm{o}}$ de notícias) & 1,865 & 2,14 & 0,00 & 9,00 \\
\hline Índice de segurança da carne suína (no de notícias) & 1,459 & 4,54 & 0,00 & 27,00 \\
\hline Índice de segurança da carne de frango (no de notícias) & 1,027 & 3,45 & 0,00 & 21,00 \\
\hline
\end{tabular}

* Séries deflacionadas pelo IGP-DI, dezembro de 2011=100.

Fonte: Elaboração própria com base em dados de USDA/FAS (2012), IEA (2012) e Ipea (2012). 


\section{Modelo econométrico das demandas por carnes no Brasil com a Incorporação de Índices de Segurança do Alimento}

A especificação base dos modelos econométricos é a da i-ésima equação da parcela do gasto Marshalliana do sistema AIDS de Deaton e Muellbauer (1980) é:

$w_{i t}=\alpha_{i t}+\sum_{j=1}^{N} \gamma_{i j} \ln p_{j t}+\beta_{i}\left(\ln x_{t}-\ln P_{t}\right)+v_{i t} \forall i$

em que, no ano $t$ e para o bem $i: w_{i t}=p_{i t} q_{i t} / x_{i t}$ é a parcela do gasto; $q_{i t}$ é o consumo em kg per capita; $p_{i t}$ e $p_{j t}$ são, respectivamente, o preço do $i$-ésimo e do $j$-ésimo bem; $x_{t}=\sum_{i=1}^{N} p_{i t} q_{i t}$ é o gasto ${ }^{18}$ per capita com os $N$ bens; $v_{i t}$ é o termo de erro da $i$-ésima equação; e $\ln P_{t}$ é o índice de preços translog:

$$
\begin{aligned}
& \ln P_{t}=a_{0}+\sum_{i=1}^{N} \alpha_{i t} \ln p_{i t}+ \\
& +1 / 2 \sum_{i=1}^{N} \sum_{j=1}^{N} \gamma_{i j} \ln p_{i t} \ln p_{j t}
\end{aligned}
$$

Schroederetal. (2000) sugerem que outras variáveis explicativas, além dos preços e gasto, devem ser incorporadas aos modelos de demanda, pois a pesquisa recente sobre a demanda por carnes nos EUA indica conclusivamente neste sentido. Assim, sugerem que sejam incluídas variáveis capazes de captar o nível de informação dos consumidores sobre aspectos de saúde relacionados ao consumo de carnes, conveniência, qualidade do alimento, grau de promoção e propaganda e características demográficas dos consumidores. Diante da indisponibilidade imediata de variáveis como estas no Brasil e objetivando minimizar os problemas advindos da omissão de dinâmica nos modelos e da potencial não consideração de não estacionaridade determinísticas nas séries, adotou-se a estratégia sugerida e utilizada por Piggott et al. (1996) e Fisher et al. (2001), incluindo-se deslocadores da demanda via modificadores

18. O gasto se iguala à renda do consumidor se este possui preferências não saciadas localmente (MAS-COLELL et al., 1996), como se assume ser o caso. dos interceptos das equações (1), como definido em (3).

$$
\begin{aligned}
& \alpha_{i t}=a_{i 0}+\tau_{i} T_{t}+\theta_{i} D_{t}+ \\
& +\sum_{m=0}^{L}\left(\phi_{i, m} b f_{t-m}+\pi_{i, m} p k_{t-m}+\kappa_{i, m} p y_{t-m}\right) \quad \forall i
\end{aligned}
$$

em que, no ano $t, \alpha_{i t}$ representa os interceptos das equações (1) e os coeficientes das variáveis In $p_{i t}$ na equação (2); $a_{i 0}$ é o intercepto da equação (3); $T_{t}$ é a variável tendência ${ }^{19}$ com valor um no ano 1975; $D$ é uma variável binária que recebe o valor zero nos anos de 1975 a 1993 e um nos anos de 1994 a 2011, que é o período pós Plano Real20; e $b f_{t-m}, p k_{t-m}$ e $p y_{t-m}$ são as variáveis índice de segurança do alimento com defasagem temporal $m$, respectivamente, para as carnes bovina, suína e de frango. Esses índices foram definidos anteriormente na seção 3 deste trabalho.

Propriedades da teoria do consumidor individual são impostas aos modelos, como segue. $\mathrm{O}$ fato de toda a renda do consumidor ser gasta (propriedade adding up) equivale a que as parcelas dos gastos somem um, o que é garantida pela imposição das condições (4); a propriedade de ausência de ilusão monetária ou homogeneidade ${ }^{21}$ de grau zero nos preços e renda é garantida pelas condições (5); e a simetria da matriz de substituição de Slutsky ${ }^{22}$ é garantida pelas condições (6).

19. A inclusão da variável tendência nas equações permite capturar mudanças estruturais nas demandas, mas ao custo de não se ter como identificar os fatores que possam tê-las causado (SCHROEDER et al., 2000).

20. O Plano Real é o plano macroeconômico para a estabilização de preços iniciado em julho de 1994.

21. Mesmo assim, tais propriedades foram impostas sem realizar testes de especificação, pois o presente trabalho não visa testar a teoria do consumidor (KEUZENKAMP e BARTEN, 1995), mas tem como um dos seus objetivos obter valores plausíveis para as elasticidades e, sendo assim, as restrições advindas da teoria da demanda devem ser importas (PHLIPS, 1974, p. 55). Procedendo assim, seguimos o que fizeram Piggott e Marsh (2004), Piggott et al. (1996) e Fisher et al. (2001) que são a base para a construção dos modelos utilizados no presente artigo.

22. Pela teoria do consumidor, a matriz de substituição de Slutsky deve ser negativa semidefinida. Como o sistema AIDS não possibilita a imposição direta das restrições que garantiriam a seminegatividade da matriz de Slutsky, apesar de estas poderem ser testadas ponto a ponto após a estimação, o sistema AIDS foi rotulado por Deaton e Muellbauer (1980) como quase ideal. 


$$
\begin{aligned}
& \sum_{i=1}^{N} a_{i 0}=1, \sum_{i=1}^{N} \tau_{i}=0, \sum_{i=1}^{N} \theta_{i}=0, \\
& \sum_{m=0}^{L} \phi_{i, m}=0, \sum_{m=0}^{L} \pi_{i, m}=0, \sum_{m=0}^{L} \kappa_{i, m}=0, \\
& \sum_{i=1}^{N} \beta_{i}=0 \text { e } \sum_{i=1}^{N} \gamma_{i j}=0 \quad \forall j \\
& \sum_{j=1}^{N} \gamma_{i j}=0 \quad \forall i \\
& \gamma_{i j}=\gamma_{j i} \quad \forall i, j
\end{aligned}
$$

O sistema de equações de demanda foi especificado para um conjunto de quatro bens: carne bovina, carne suína, carne de frango e "outros bens de consumo", seguindo o que fizeram Marsh et al. (2004) em uma aplicação pioneira desse procedimento a um sistema de equações de demanda Rotterdam para carnes nos EUA.

Vale mencionar que, se tivessem sido utilizados sistemas de equações de demanda com apenas três bens (carne bovina, carne suína e de frango), as condições (4) fariam com que potenciais mudanças estruturais nas demandas por carnes necessariamente se anulassem. A especificação de um sistema de equações com quatro bens permite, por exemplo, que as demandas de cada carne possam apresentar tanto mudança estrutural positiva quanto negativa. Além disso, tal formulação elimina a possibilidade de endogeneidade da variável gasto, o que provavelmente ocorreria em um sistema de equações estimado com apenas os três tipos de carnes, pois, neste caso, a variável gasto corresponderia ao próprio gasto per capita com tais carnes. No sistema de demanda com quatro bens, a variável gasto per capita com consumo é, muito provavelmente, exógena (BRESTER e SCHROEDER, 1995). Finalmente, um sistema com quatro bens permite investigar a possibilidade de substituição entre os tipos de carnes e outros bens de consumo (MARSH et al., 2004).

Em estudos com séries de tempo, a ocorrência de autocorrelação ou correlação serial dos erros é um problema recorrente. Por exemplo, Fisher et al. (2006) assumem a presença de autocorrelação e, assim, já impõem, a priori, correções para correlação serial de primeira ordem dos erros nos sistemas de equações não lineares de demanda estimados por eles. Ao contrário do que fizeram
Fisher et al. (2006), investigaremos se há autocorrelação e, para tanto, testaremos duas formas alternativas de correção do problema. Para tanto, serão estimadas seis especificações alternativas dos sistemas de equações descritos pelas equações (1) a (6), incluindo ou não os índices de segurança do alimento e seguindo o procedimento para correção da autocorrelação, pioneiramente proposta por Berndt e Savin (1975) e resumidamente descrito a seguir.

\subsection{Correções e teste para autocorrelação dos erros}

Os passos descritos a seguir objetivam apresentar o procedimento de Berndt e Savin (1975) que foi empregado no presente artigo para testar e corrigir a autocorrelação de primeira ordem dos erros dos modelos.

Considerando-se $v_{t}$, um vetor $N \times 1$ formado pelos erros aleatórios $v_{i t}$ do sistema de equações de demanda (1) no tempo $t$ e admitindo-se que os erros do sistema são autorregressivos de primeira ordem, tal que: $v_{t}=R v_{t-1}+\varepsilon_{t}, t=2, \ldots, T$, em que $\varepsilon_{t}$ é um vetor $N \times 1$ de erros aleatórios independentemente, identicamente e normalmente distribuídos, com médias zero e matriz de variância-covariância $\Sigma$ e $R$ é uma matriz de autocorrelação com $N \times N$ parâmetros desconhecidos. Como primeiro passo, Berndt e Savin (1975) mostram que, para um sistema com erros desse tipo, a propriedade adding up implica que: a matriz de covariância $\Sigma$ é singular; e a soma dos elementos de cada coluna da matriz $R$ se iguala a uma constante $k$ desconhecida, tal que $1^{\prime} R=k^{\prime}$, em que 1 é um vetor $N \times 1$ de uns; $k$ é um vetor $N \times 1$ de elementos com valores iguais a constante $k$ e o símbolo' denota a transposta.

No segundo passo, Berndt e Savin (1975) demonstram que as restrições $1^{\prime} R=k^{\prime}$ podem ser transformadas em restrições mais facilmente tratáveis da forma $1^{\prime} \bar{R}=0$, em que $\bar{R}$ é uma matriz de dimensão $N \times(N-1)$ formada pelos elementos $R_{i j}-R_{i n}, \operatorname{com} i=1, \ldots, N ; j=1, \ldots, n-1$, em que: $R_{i j}$ denota o elemento linha $i$, coluna $j$ da matriz $R$ e $n$ indexa a última equação do sistema, exata- 
mente aquela eliminada de modo a contornar o problema de singularidade de $\Sigma$.

No terceiro passo, Berndt e Savin (1975) definem $\bar{R}_{n}$ como a matriz formada pelas primeiras $N-1$ linhas de, $\bar{R}$ sendo, portanto, de dimensão $(N-1) \times(N-1)$. Como serão os primeiros $N-1$ elementos de $\bar{R}_{n}$ que serão estimados, e não os elementos de $\bar{R}$ ou $R$, qualquer restrição sobre $\bar{R}$ ou $R$ pode ser facilmente imposta a $\bar{R}_{n}$ após a estimação do sistema de equações (PIGGOTT et al., 1996). Dessa forma, a estimação por máxima verossimilhança do sistema constituído pelas $N-1$ equações será invariante à equação que foi eliminada, como desejado.

Seguindo o que fizeram Piggott et al. (1996), correções para autocorrelação de primeira ordem nos erros foram incorporadas modificando-se o sistema AIDS (equações 1) para:

$W_{t}=\bar{R}_{n} W_{t-1}+W_{t}\left(p_{t}, x_{t}\right)-\bar{R}_{n} W_{t-1}\left(p_{t-1}, x_{t-1}\right)+\varepsilon_{t}$

em que $W_{t}$ é uma matriz $(N-1) \times 1$ de parcelas do gasto observadas para os $N-1$ bens incluídos no sistema a ser estimado; e $W_{t}\left(p_{t}, x_{t}\right)$ é uma matriz $(N-1) \times 1$ de equações de parcelas do gasto do sistema AIDS definidas conforme equações (1).

No presente estudo, os sistemas de demanda foram estimados com base na formulação em (7), utilizando, para tanto: uma matriz nula $\bar{R}_{n}$ denominada $N-R^{\text {matriz }}$ em que cada elemento é zero ${ }^{23}$; uma matriz diagonal $\bar{R}_{n}$ denominada $D-R^{\text {matriz }}$ em que cada elemento da diagonal principal é igual a uma mesma constante desconhecida e os demais elementos são zeros; e uma matriz completa $\bar{R}_{n}$ denominada $F-R^{\text {matriz }}$ em que cada elemento pode assumir qualquer valor. As matrizes $N-R^{\text {matriz }}$, $D-R^{\text {matriz }}$ e $F-R^{\text {matriz }}$ são de dimensão $(N-1) \times(N-1)$.

Ao todo, estimam-se seis especificações alternativas para os sistemas de equações formados pelas equações (1) a (7) considerando-se: três estruturas de correções para a autocorrelação dos erros ( $N-R^{\text {matriz }}, D-R^{\text {matriz }}$ e $\left.F-R^{\text {matriz }}\right)$, a não inclusão das séries de índices agregados de segurança do alimento (No - FS) e a inclusão das séries de

23. Caso em que não há correção para autocorrelação de primeira ordem. índices agregados de segurança do alimento sem defasagem $(L=0)$. Cada um dos modelos foi estimado pelo método Full Information Maximum Likelihood (FIML) e método interativo não linear de regressão aparentemente não relacionada (ITSUR), os quais são equivalentes no caso de sistemas de equações com erros aparentemente não relacionados (SUR) e normalmente distribuídos (GREENE, 2003, p. 357; BARNETT, 1976). Os estimadores FIML são assintoticamente eficientes, como é o caso, para modelos simultâneos não lineares, sob a hipótese de que os erros contemporâneos são conjuntamente e normalmente distribuídos (QUANTITATIVE MICRO SOFTWARE, 2010).

Em um levantamento sobre o estado da arte na modelagem da demanda do consumidor, Barnett e Serletis (2008) detectaram que ainda não há trabalhos que tratem das modificações necessárias aos métodos de cointegração tradicionais para modelos lineares de modo a viabilizar a aplicação destes métodos na estimação de sistemas de equações de demanda não lineares. Por conta disto, problemas com a não estacionaridade das séries de tempo, no contexto de estimação de sistemas de equações não lineares, têm sido usualmente ignorados ou tratados com a utilização de métodos de cointegração originalmente desenvolvidos para sistemas lineares (BARNETT e SERLETIS, 2008).

Métodos que lidam com a não estacionaridade das séries em modelos lineares não podem ser diretamente aplicados a modelos de demanda não lineares (LEWBEL e NG, 2005) como, por exemplo, o sistema AIDS. Portanto, para fins de análise de cointegração, admite-se que inferências baseadas nos resíduos podem ser confiáveis se estes são estacionários, tal que, seguindo Fisher et al. (2001), antes de se efetuar os testes de comparação dos modelos, executaram-se testes de raiz unitária dos resíduos dos modelos. Este procedimento está em linha com o método em dois estágios de Engle e Granger (1987), segundo o qual, para que variáveis em modelos lineares possam estar cointegradas é necessário que os resíduos da regressão sejam estacionários. 


\section{Resultados e discussão}

Nessa seção, seguimos os seguintes passos: primeiro, descrevemos os procedimentos utilizados na estimação dos modelos formulados segundo as equações (1) a (7). O segundo passo consiste em apresentar os testes de raiz unitária dos erros dos modelos. Caso se conclua que os erros são estacionários, admitiremos que as variáveis nos modelos podem ser cointegradas, o que justifica a realização dos passos subsequentes. $\mathrm{O}$ terceiro passo consiste na apresentação dos resultados das estimações dos seis modelos especificados segundo as equações (1) a (7), considerando modelos sem a inclusão das variáveis "índices de segurança do alimento" e com a inclusão destas variáveis sem defasagem temporal $(L=0)$. No quarto passo, são apresentados os testes de especificação de razão de verossimilhança empregados para testar se crises de segurança do alimento impactam as demandas por carne no Brasil e, ao mesmo tempo, selecionar, dentre as seis especificações utilizadas, a preferida. $\mathrm{O}$ quinto passo consiste em apresentar as estimativas do modelo preferido e apresentar e discutir as elasticidades estimadas a partir deste modelo.

A Tabela 3 apresenta, baseando-se nos valores críticos obtidos por MacKinnon (1996), os p-valores do teste Dickey-Fuller (ADF) aumentado (Dickey e Fuller, 1981) e do teste não paramétrico $Z\left(t_{a}\right)$ de Phillips (1987) e Phillips e Perron (1988).

Com base nos $p$-valores apresentados na Tabela 3, conclui-se que a hipótese de que há raiz unitária nas séries de resíduos é rejeitada em cada modelo estimado, por exemplo, ao nível de $1 \%$ de probabilidade. Como os resíduos das equações dos modelos são estacionários, conclui-se que as variáveis nos modelos podem ser cointegradas o que justifica a estimação desses modelos (FISHER et al., 2001).

\subsection{Testes de hipóteses e seleção do modelo preferido}

O teste usual de razão de verossimilhança (teste $L R$ ) é, em amostras pequenas, viesado a favor da rejeição de restrições impostas a modelos de equações de demanda (MOSCHINI et al., 1994). Apesar de não existir uma forma inequívoca de se ajustar o teste $L R$ de modo a atenuar tal viés, Moschini et al. (1994) verificam que o ajuste proposto por Italianer (1975) apresenta bom desempenho quando aplicado a sistemas não lineares de equações de demanda. A estatística do teste $L R$ ajustado de Italianer (1975) é:

$L R s=\left(\left(M T-0.5\left(\left(k^{u}+k^{\prime}\right)-M(M+1)\right)\right) / M T\right) L R$

em que $M$ é o número de equações incluídas na estimação do modelo; $T$ é o tamanho da amostra; $k^{u}$ e $k^{r}$ são o número de parâmetros nos modelo irrestrito e restrito; $L R=2\left(L L^{u}-L L^{r}\right)$ é a estatística do teste de razão de verossimilhança; e $L L^{u}$ e $L L^{r}$ são, respectivamente, os máximos valores da função logaritmo da verossimilhança nos modelos irrestrito e restrito.

Tabela 3. Testes de raiz unitária dos resíduos dos modelos ( $p$-valores)

\begin{tabular}{|c|c|c|c|c|c|c|}
\hline \multirow{2}{*}{ Modelo } & \multicolumn{2}{|c|}{ Equação da Carne Bovina } & \multicolumn{2}{|c|}{ Equação da Carne Suína } & \multicolumn{2}{|c|}{ Equação da Carne de Frango } \\
\hline & ADF & $Z\left(t_{a}\right)$ & ADF & $Z\left(t_{a}\right)$ & ADF & $Z\left(t_{a}\right)$ \\
\hline$N-R^{\text {matriz }}, N o-F S$ & 0,0001 & 0,0001 & 0,0001 & 0,0000 & 0,0001 & 0,0001 \\
\hline$N-R^{\text {matriz }}, L=0$ & 0,0001 & 0,0001 & 0,0002 & 0,0000 & 0,0002 & 0,0002 \\
\hline$D-R^{\text {matriz }}, N o-F S$ & 0,0000 & 0,0000 & 0,0000 & 0,0000 & 0,0577 & 0,0001 \\
\hline$D-R^{\text {matriz }}, L=0$ & 0,0000 & 0,0000 & 0,0000 & 0,0000 & 0,0000 & 0,0000 \\
\hline$F-R^{\text {matriz }}, N o-F S$ & 0,0000 & 0,0000 & 0,0002 & 0,0002 & 0,0000 & 0,0000 \\
\hline$F-R^{\text {matriz }}, L=0$ & 0,0000 & 0,0000 & 0,0002 & 0,0000 & 0,0001 & 0,0001 \\
\hline
\end{tabular}

Notas: $p$-valores para a hipótese nula de que há uma raiz unitária ou não estacionaridade; ADF denota teste Dickey-Fuller aumentado e $Z\left(t_{n}\right)$, teste de Phillips-Perron.

Fonte: Elaboração própria. 
Tabela 4. Testes de hipótese para a significância dos índices de segurança do alimento e para as correções para autocorrelação

\begin{tabular}{|c|c|c|c|c|c|}
\hline & \multirow{2}{*}{$\begin{array}{c}\text { Não Inclusão dos Índices de } \\
\text { Segurança do Alimento } \\
H_{0}: \text { No-FS } \\
\end{array}$} & & \multicolumn{3}{|c|}{ Correções para Autocorrelação } \\
\hline & & & $H_{0}: N-R^{\text {matriz }}$ & $H_{0}: D-R^{\text {matriz }}$ & $H_{0}: N-R^{\text {matriz }}$ \\
\hline Modelo & $H_{1}: L=0$ & Modelo & $H_{1}: D-R^{\text {matriz }}$ & $H_{1}: F-R^{\text {matriz }}$ & $H_{1}: F-R^{\text {matriz }}$ \\
\hline N-R $\mathrm{R}^{\text {matriz }}$ & 3,984 & No-FS & $7,498^{*}$ & $62,781^{*}$ & $70,285^{*}$ \\
\hline D-R matriz $^{\text {mat }}$ & 14,474 & $L=0$ & $17,655^{*}$ & $53,412^{*}$ & $70,927^{*}$ \\
\hline F-R ${ }^{\text {matriz }}$ & 6,517 & & & & \\
\hline g.l. & 9 & & 1 & 8 & 9 \\
\hline$\chi_{5 \%, \text { g.l. }}^{2}$ & 16,919 & & 3,841 & 15,507 & 16,919 \\
\hline
\end{tabular}

* Denota a rejeição de $H_{0}$ ao nível de $5 \%, L=0$ denota que as séries de índices de segurança do alimento foram incluídas sem defasagens no modelo; No-FS indica que o modelo não incorpora os índices de segurança do alimento como regressores; g.l. denota graus de liberdade. Os valores apresentados são as estatísticas LRs calculadas segundo a equação (8).

Fonte: Elaboração própria.

A estatística razão da verossimilhança ajustada (LRs) segue assintoticamente uma distribuição $\chi^{2}$ com graus de liberdade igual à diferença entre o número de parâmetros no modelo irrestrito e restrito. A hipótese nula do teste $L R$ ajustado é de que os parâmetros adicionados ao modelo restrito são conjuntamente zero, ou seja, o modelo restrito é o correto. A Tabela 4 apresenta os resultados dos testes de hipóteses para autocorrelação dos erros e para a não necessidade de inclusão dos índices de segurança do alimento.

Os resultados dos testes de razão da verossimilhança ajustada ( $L R s)$ apresentados nas colunas de 4 a 6 da Tabela 4 levam às seguintes conclusões ${ }^{24}$ com respeito à preferência entre pares de especificações dos modelos: $D-R^{\text {matriz }} \succ N-R^{\text {matriz }}$, $F-R^{\text {matriz }} \succ D-R^{\text {matriz }}$ e $F-R^{\text {matriz }} \succ N-R^{\text {matriz }}$. Com base nisto, a ordem final de preferência com relação aos modelos é: F-R ${ }^{\text {matriz }} \succ D-R^{\text {matriz }} \succ N-R^{\text {matriz }}$, o que implica concluir que há autocorrelação de primeira ordem dos resíduos e que o modelo estimado com $F-R^{\text {matriz }}$ corrige o problema.

O segundo passo nos testes de especificação consiste em testar se os efeitos dos índices de segurança do alimento são conjuntamente zero. Para tanto, partindo do resultado obtido no primeiro passo, considera-se apenas a especificação do sistema com a matriz completa $F-R^{\text {matriz }}$. Assim, avaliando-se o resultado do teste apresentado na Tabela 4, coluna dois, referente à linha $F-R^{\text {matriz, }}$

24. O símbolo $\succ$ significa "é estritamente preferível a". observa-se que não é possível rejeitar a hipótese de que os efeitos dos índices de segurança do alimento são conjuntamente zero. Em outras palavras, não é possível rejeitar a hipótese de que crises de segurança do alimento não afetam as demandas da carne bovina, suína e de frango no Brasil. De fato, esse resultado é robusto, pois também não é possível rejeitar esta mesma hipótese nos modelos $N-R^{\text {matriz }}$ e $D-R^{\text {matriz }}$ (vide Tabela 4, coluna 2).

Assim, os testes de razão de verossimilhança ajustada levam à conclusão de que o modelo preferido é aquele que não inclui os índices de segurança do alimento e utiliza uma $F-R^{\text {matriz }}$ para corrigir para autocorrelação. As estimativas dos parâmetros, os erros-padrão e as medidas de qualidade do ajuste para esta especificação do sistema de equações são apresentados na Tabela 5. Para fins de comparação, na Tabela 5 são apresentadas além das estimativas do modelo $F-R^{\text {matriz }}$ No-FS também o com $L=0$, ou seja, o modelo que inclui os índices de segurança do alimento.

Corroborando a conclusão de que crises de segurança do alimento não afetam as demandas da carne bovina, suína e de frango no Brasil, observa-se pela Tabela 5 que as estimativas dos coeficientes $\left(\phi_{b 0}, \pi_{b 0}, \kappa_{b 0}, \phi_{p 0}, \pi_{p 0}, \kappa_{p 0}, \phi_{c 0}, \pi_{c 0}\right.$, e $\left.\kappa_{c 0}\right)$ dos índices de segurança do alimento na coluna referente ao Modelo com $F-R^{\text {matriz, }} L=0$ são todas muito próximas a zero. Além disso, exceto para $\phi_{p 0}$ (coeficiente do índice de segurança do alimento para a carne bovina na equação de demanda da 
Tabela 5. Resultados das estimações dos modelos No-FS e $L=0$ ambos estimados com $F$ - $R^{\text {matriz }}$

\begin{tabular}{|c|c|c|}
\hline Parâmetro & $\begin{array}{l}\text { Modelo com F-R } \\
\text { No-FS }\end{array}$ & $\begin{array}{c}\text { Modelo com F-R }{ }^{\text {matriz }} \\
L=0\end{array}$ \\
\hline$a_{0}$ & $\begin{array}{l}-2,397^{*} \\
(1,282)\end{array}$ & $\begin{array}{c}-0,429 \\
(1,336)\end{array}$ \\
\hline$\alpha_{\mathrm{b} 0}$ & $\begin{array}{l}0,480^{*} \\
(0,063)\end{array}$ & $\begin{array}{l}0,703^{*} \\
(0,083)\end{array}$ \\
\hline$\alpha_{\mathrm{p} 0}$ & $\begin{array}{l}0,125^{*} \\
(0,028)\end{array}$ & $\begin{array}{l}0,076^{*} \\
(0,027)\end{array}$ \\
\hline$\alpha_{\mathrm{c} 0}$ & $\begin{array}{l}0,159^{*} \\
(0,026)\end{array}$ & $\begin{array}{l}0,110^{*} \\
(0,018)\end{array}$ \\
\hline$\gamma_{\mathrm{bb}}$ & $\begin{array}{l}0,019^{*} \\
(0,002)\end{array}$ & $\begin{array}{l}0,015^{*} \\
(0,002)\end{array}$ \\
\hline$\gamma_{\mathrm{bp}}$ & $\begin{array}{l}-0,008^{*} \\
(0,001)\end{array}$ & $\begin{array}{l}-0,008^{*} \\
(0,001)\end{array}$ \\
\hline$\gamma_{\mathrm{bc}}$ & $\begin{array}{l}-0,004^{*} \\
(0,001)\end{array}$ & $\begin{array}{l}-0,004^{*} \\
(0,001)\end{array}$ \\
\hline$\gamma_{\mathrm{pp}}$ & $\begin{array}{l}0,010^{*} \\
(0,001)\end{array}$ & $\begin{array}{l}0,010^{*} \\
(0,001)\end{array}$ \\
\hline$\gamma_{p c}$ & $\begin{array}{c}-3,78 \times 10^{-4} \\
(0,0009)\end{array}$ & $\begin{array}{l}-0,001 \\
(0,001)\end{array}$ \\
\hline$\gamma_{c c}$ & $\begin{array}{l}0,006^{*} \\
(0,001)\end{array}$ & $\begin{array}{l}0,006^{*} \\
(0,001)\end{array}$ \\
\hline$\beta_{\mathrm{b}}$ & $\begin{array}{l}-0,037^{*} \\
(0,005)\end{array}$ & $\begin{array}{l}-0,035^{*} \\
(0,007)\end{array}$ \\
\hline$\beta_{\mathrm{p}}$ & $\begin{array}{l}-0,015 \\
(0,001)\end{array}$ & $\begin{array}{l}-0,016^{*} \\
(0,001)\end{array}$ \\
\hline$\beta_{\mathrm{c}}$ & $\begin{array}{l}-0,010 \\
(0,001)\end{array}$ & $\begin{array}{l}-0,008^{*} \\
(0,001)\end{array}$ \\
\hline$\tau_{\mathrm{b}}$ & $\begin{array}{l}6,96 \times 10^{-4 *} \\
(0,0001)\end{array}$ & $\begin{array}{l}-0,001 \\
(0,001)\end{array}$ \\
\hline$\tau_{\mathrm{p}}$ & $\begin{array}{l}2,61 \times 10^{-4 *} \\
\left(3,88 \times 10^{-5}\right)\end{array}$ & $\begin{array}{l}0,0004^{*} \\
(0,000)\end{array}$ \\
\hline$\tau_{\mathrm{c}}$ & $\begin{array}{l}5,89 \times 10^{-4 *} \\
\left(5,13 \times 10^{-5}\right)\end{array}$ & $\begin{array}{l}0,0003 \\
(0,000)\end{array}$ \\
\hline$\theta_{\mathrm{b}}$ & $\begin{array}{c}0,004 \\
(0,004)\end{array}$ & $\begin{array}{c}0,003 \\
(0,004)\end{array}$ \\
\hline$\theta_{\mathrm{p}}$ & $\begin{array}{c}0,001 \\
(0,001)\end{array}$ & $\begin{array}{l}0,0004 \\
(0,000)\end{array}$ \\
\hline$\theta_{\mathrm{c}}$ & $\begin{array}{c}0,000 \\
(0,001)\end{array}$ & $\begin{array}{c}0,001 \\
(0,001)\end{array}$ \\
\hline$\rho_{\mathrm{bb}}$ & $\begin{array}{l}0,303^{*} \\
(0,109)\end{array}$ & $\begin{array}{l}0,594^{*} \\
(0,144)\end{array}$ \\
\hline$\rho_{\mathrm{bp}}$ & $\begin{array}{l}-1,244 \\
(0,860)\end{array}$ & $\begin{array}{l}-1,861 \\
(1,400)\end{array}$ \\
\hline$\rho_{\mathrm{bc}}$ & $\begin{array}{l}0,859^{*} \\
(0,699)\end{array}$ & $\begin{array}{l}1,773 \\
(0,979)\end{array}$ \\
\hline$\rho_{\mathrm{pb}}$ & $\begin{array}{l}-0,051^{*} \\
(0,018)\end{array}$ & $\begin{array}{l}-0,044^{*} \\
(0,017)\end{array}$ \\
\hline$\rho_{\mathrm{pp}}$ & $\begin{array}{c}0,153 \\
(0,142)\end{array}$ & $\begin{array}{c}0,073 \\
(0,118)\end{array}$ \\
\hline$\rho_{\mathrm{pc}}$ & $\begin{array}{l}-0,181 \\
(0,130)\end{array}$ & $\begin{array}{l}-0,400^{*} \\
(0,101)\end{array}$ \\
\hline$\rho_{\mathrm{cb}}$ & $\begin{array}{c}0,011 \\
(0,015)\end{array}$ & $\begin{array}{c}0,008 \\
(0,023)\end{array}$ \\
\hline$\rho_{\mathrm{cp}}$ & $\begin{array}{c}0,078 \\
(0,156)\end{array}$ & $\begin{array}{l}-0,218 \\
(0,194)\end{array}$ \\
\hline$\rho_{\mathrm{cc}}$ & $\begin{array}{l}0,616^{*} \\
(0,136)\end{array}$ & $\begin{array}{l}0,651^{*} \\
(0,163)\end{array}$ \\
\hline$\phi_{\mathrm{b} 0}$ & - & $\begin{array}{l}1,21 \times 10^{-4} \\
\left(2,44 \times 10^{-4}\right)\end{array}$ \\
\hline
\end{tabular}




\begin{tabular}{|c|c|c|}
\hline$\pi_{\mathrm{b} 0}$ & - & $\begin{array}{c}1,37 \times 10^{-4} \\
\left(1,14 \times 10^{-4}\right)\end{array}$ \\
\hline$\kappa_{\mathrm{b} 0}$ & - & $\begin{array}{c}5,05 \times 10^{-5} \\
\left(1,47 \times 10^{-4}\right)\end{array}$ \\
\hline$\phi_{\mathrm{p} 0}$ & - & $\begin{array}{l}8,82 \times 10^{-5 *} \\
\left(3,41 \times 10^{-5}\right)\end{array}$ \\
\hline$\pi_{\mathrm{p} 0}$ & - & $\begin{array}{c}2,05 \times 10^{-5} \\
\left(1,58 \times 10^{-5}\right)\end{array}$ \\
\hline$\kappa_{\mathrm{p} 0}$ & - & $\begin{array}{l}5,52 \times 10^{-5 *} \\
\left(1,97 \times 10^{-5}\right)\end{array}$ \\
\hline$\phi_{\mathrm{c} 0}$ & - & $\begin{array}{l}-5,34 \times 10^{-5} \\
\left(3,83 \times 10^{-5}\right)\end{array}$ \\
\hline$\pi_{\mathrm{c} 0}$ & - & $\begin{array}{r}2,31 \times 10^{-5} \\
\left(1,86 \times 10^{-5}\right)\end{array}$ \\
\hline$\kappa_{\mathrm{c} 0}$ & - & $\begin{array}{l}-6,81 \times 10^{-6} \\
\left(2,27 \times 10^{-5}\right) \\
\end{array}$ \\
\hline Logaritmo da Verossimilhança & 619,587 & 621,767 \\
\hline $\mathrm{R}^{2}$ Ajustado da Equação da Carne Bovina & 0,656 & 0,813 \\
\hline $\mathrm{R}^{2}$ Ajustado da Equação da Carne Suína & 0,894 & 0,846 \\
\hline $\mathrm{R}^{2}$ Ajustado da Equação da Carne de Frango & 0,895 & 0,665 \\
\hline
\end{tabular}

Notas: Números em parênteses são erros-padrão; * Denota estatisticamente significativo pelo ao nível de 5\%; os subscritos $b, p$ e $c$ denotam carne bovina, carne suína e carne de frango; $\alpha_{0}$ é o intercepto da equação do índice de preço translog (equação (2)); $\alpha_{b 0}, \alpha_{p 0}$ e $\alpha_{c 0}$ são os interceptos respectivamente para as equações da parcela do gasto com carne bovina, suína e de frangos (vide equação (3); $\gamma_{b b}, \gamma_{b p}, \gamma_{b c}, \gamma_{p p}, \gamma_{p c}$ e $\gamma_{c c}$ são coeficientes das equações (1) e (2); $\beta_{b}$, $\beta_{p}$ e $\beta_{c}$ são coeficientes das variáveis logaritmo natural do gasto real, (In $\left.x t-\operatorname{In} P t\right)$, com carnes nas equações (1) das parcelas dos gastos AIDS; $\tau_{b}$, $\tau_{p}$ e e $\tau_{c}$ são os coeficientes da variável tendência e $\theta_{b}, \theta_{p}$ e $\theta_{c}$ são os coeficientes da variável binária para o plano Real nas equações (3) dos deslocadores dos interceptos das equações do modelo AIDS (equação (1)); $\rho_{b b r}$ $\rho_{b c}$ e $\rho_{b p}$ são os elementos da primeira linha, $\rho_{p b}, \rho_{p c}$ e $\rho_{p p}$, da segunda linha e $\rho_{c b}, \rho_{c c}$ e $\rho_{c p}$, da terceira linha da matriz $\bar{R}_{n}$ denominada F-R ${ }^{\text {matrizz; }} \phi_{b 0}, \pi_{b 0}$ e $\kappa_{b 0}$ são os coeficientes dos índices de segurança do alimento para a carne bovina, suína e de frango na equação (3) da carne bovina; $\phi_{p 0}, \pi_{p 0}$ e $\kappa_{p 0}$ são os coeficientes dos índices de segurança do alimento para a carne bovina, suína e de frango na equação (3) da carne suína; e $\phi_{c 0}, \pi_{c 0}$ e $\kappa_{c 0}$. são os coeficientes dos índices de segurança do alimento para a carne bovina, suína e de frango na equação (3) da carne de frango.

Fonte: Elaboração própria.

carne suína) e $\kappa_{p 0}$ (coeficiente do índice de segurança do alimento para a carne suína na equação de demanda da carne suína) que são individualmente estatisticamente significativos, os outros sete coeficientes dos índices de segurança do alimento não são estatisticamente individualmente significativos.

Ainda pela Tabela 5 é possível observar que os coeficientes $\theta_{b}, \theta_{p}$ e $\theta_{c}$ não são estatisticamente significantes, indicando que o Plano Real não afetou as demandas por carnes e outros bens de consumo. Já os resultados para os coeficientes $\tau_{b}$, $\tau_{p}$ e $\tau_{c}$ da variável tendência nas equações (3) dos deslocadores dos interceptos das equações do modelo AIDS (equação (1)) foram positivas e individualmente estatisticamente significativas. Com isso, conclui-se que há mudanças estruturais nas demandas no sentido do aumento do consumo de carnes no Brasil, mas que, devido à limitação associada ao uso da variável tendência, não há como identificar os fatores que possam estar causando-as (SCHROEDER et al., 2000).

\subsection{Elasticidades das demandas por carnes}

A Tabela 6 apresenta as médias das elasticidades calculadas para cada observação das elasticidades-preços Marshalliana e Hicksiana e elasticidades-gasto ${ }^{25}$ (aproximadamente, elastici-

25. As equações utilizadas para calcular, respectivamente, as elasticidades-preço Marshallianas $\left(\eta_{i j}\right)$ e as elasticidades-gasto $\left(\eta_{i x}\right)$ são:

$h_{i j}=\frac{w_{i}}{\ln p_{j}} \frac{1}{w_{i}}-d_{i j}=\frac{g_{i j}-b_{i}\left(a_{j}+\stackrel{\circ}{a}_{k=1}^{N} g_{j k} \log p_{k}\right)}{w_{i}}-d_{i j}{ }^{\mu} i, j$

$h_{i x}=\frac{w_{i}}{\ln x} \frac{1}{w_{i}}+1=\frac{b_{i}}{w_{i}}+1^{*} i$

em que $\delta_{i j}$ é o delta de Kronecker, tal que, $\delta_{i j}=1$ para $i=j$ e, caso contrário, $\delta_{i j}=0$. 
Tabela 6. Estimativas e desvios-padrão das elasticidades preço e gasto (renda) para o modelo AIDS estimado com F-R ${ }^{\text {matriz }}$ e No-FS

\begin{tabular}{|c|c|c|c|c|c|}
\hline \multicolumn{2}{|c|}{ Elasticidades-Preço Marshallianas } & \multicolumn{2}{|c|}{ Elasticidades-Gasto } & \multicolumn{2}{|c|}{ Elasticidades-Preço Hicksianas } \\
\hline$\eta_{\mathrm{bb}}$ & $\begin{array}{l}-0,570^{*} \\
(0,083)\end{array}$ & $\eta_{b x}$ & $\begin{array}{l}0,163^{*} \\
(0.150)\end{array}$ & $\varepsilon_{\mathrm{bb}}$ & $\begin{array}{l}-0,561^{*} \\
(0,075)\end{array}$ \\
\hline$\eta_{\mathrm{bp}}$ & $\begin{array}{l}0,100^{*} \\
(0,023)\end{array}$ & $\eta_{\mathrm{px}}$ & $\begin{array}{l}-0,158^{*} \\
(0,198)\end{array}$ & $\varepsilon_{\mathrm{bp}}$ & $\begin{array}{l}0,102^{*} \\
(0,020)\end{array}$ \\
\hline$\eta_{\mathrm{bc}}$ & $\begin{array}{l}0,133^{*} \\
(0,027)\end{array}$ & $\eta_{c x}$ & $\begin{array}{c}0,055 \\
(0,265)\end{array}$ & $\varepsilon_{\mathrm{bc}}$ & $\begin{array}{l}0,135^{*} \\
(0,025)\end{array}$ \\
\hline$\eta_{\mathrm{bo}}$ & $\begin{array}{l}0,174^{*} \\
(0,033)\end{array}$ & $\eta_{\text {ox }}$ & $\begin{array}{c}1,068^{*} \\
(0,0008)\end{array}$ & $\varepsilon_{\mathrm{bo}}$ & $\begin{array}{l}0,324^{*} \\
(0,121)\end{array}$ \\
\hline$\eta_{\mathrm{pb}}$ & $\begin{array}{l}0,562^{*} \\
(0,118)\end{array}$ & & & $\varepsilon_{\mathrm{pb}}$ & $\begin{array}{l}0,556^{*} \\
(0,110)\end{array}$ \\
\hline$\eta_{\mathrm{pp}}$ & $\begin{array}{l}-0,840^{*} \\
(0,031)\end{array}$ & & & $\varepsilon_{\mathrm{pp}}$ & $\begin{array}{l}-0,842^{*} \\
(0,029)\end{array}$ \\
\hline$\eta_{\mathrm{pc}}$ & $\begin{array}{l}0,190^{*} \\
(0,039)\end{array}$ & & & $\varepsilon_{\mathrm{pc}}$ & $\begin{array}{l}0,188^{*} \\
(0,037)\end{array}$ \\
\hline$\eta_{\mathrm{po}}$ & $\begin{array}{l}0,246^{*} \\
(0,031)\end{array}$ & & & $\varepsilon_{\mathrm{po}}$ & $\begin{array}{l}0,099^{*} \\
(0,176)\end{array}$ \\
\hline$\eta_{\mathrm{cb}}$ & $\begin{array}{l}0,456^{*} \\
(0,121)\end{array}$ & & & $\varepsilon_{\mathrm{cb}}$ & $\begin{array}{l}0,460^{*} \\
(0,111)\end{array}$ \\
\hline$\eta_{\mathrm{cp}}$ & $\begin{array}{l}0,120^{*} \\
(0,033)\end{array}$ & & & $\varepsilon_{\mathrm{cp}}$ & $\begin{array}{l}0,121^{*} \\
(0,029)\end{array}$ \\
\hline$\eta_{\mathrm{cc}}$ & $\begin{array}{l}-0,841^{*} \\
(0,039)\end{array}$ & & & $\varepsilon_{\mathrm{cc}}$ & $\begin{array}{l}-0,839^{*} \\
(0,036)\end{array}$ \\
\hline$\eta_{\mathrm{co}}$ & $\begin{array}{l}0,209^{*} \\
(0,078)\end{array}$ & & & $\varepsilon_{\mathrm{co}}$ & $\begin{array}{l}0,259^{*} \\
(0,176)\end{array}$ \\
\hline$\eta_{\mathrm{ob}}$ & $\begin{array}{l}-0,041^{*} \\
(0,001)\end{array}$ & & & $\varepsilon_{\mathrm{ob}}$ & $\begin{array}{l}0,008^{*} \\
(0,009)\end{array}$ \\
\hline$\eta_{\text {op }}$ & $\begin{array}{l}-0,011^{*} \\
(0,0004)\end{array}$ & & & $\varepsilon_{\mathrm{op}}$ & $\begin{array}{l}0,004^{*} \\
(0,003)\end{array}$ \\
\hline$\eta_{\mathrm{oc}}$ & $\begin{array}{l}-0,013^{*} \\
(0,0004)\end{array}$ & & & $\varepsilon_{\mathrm{oc}}$ & $\begin{array}{l}-0,000 \\
(0,003)\end{array}$ \\
\hline$\eta_{\mathrm{oo}}$ & $\begin{array}{l}-1,003^{*} \\
(0,002) \\
\end{array}$ & & & $\varepsilon_{\mathrm{oo}}$ & $\begin{array}{l}-0,012 * \\
(0,013) \\
\end{array}$ \\
\hline
\end{tabular}

Notas: Números em parênteses são desvios padrão; *Denota que a estimativa é estatisticamente diferente de zero pelo teste $t$ ao nível de $5 \%$; $\eta_{i j}$ e $\eta_{i j}$ denotam elasticidades-preço Marshallianas e Hicksianas da demanda do $i$-ésimo bem com relação ao preço do $j$-ésimo bem; e $\eta_{i x}$ denota a elasticidade-gasto do $i$-ésimo bem, com $i$ e $j=b$ para carne bovina, $p$ para carne suína, $c$ para carne de frango, e $o$ para os outros bens de consumo.

Fonte: Elaboração própria.

dades-renda) para o modelo selecionado, que é o sistema AIDS estimado com a matriz $\bar{R}_{n}, F-R^{\text {matriz }}$ e No-FS (sem índices de segurança do alimento).

$\mathrm{Na}$ Tabela 6, as elasticidades próprio-preço Marshallianas das carnes bovina $(-0,570)$, suína $(-0,840)$ e de frango $(-0,841)$ e também para os outros bens de consumo $(-1,003)$ indicam que as demandas por carnes são inelásticas e a demanda por outros bens de consumo é elástica. Santana (1999) estimou elasticidades próprio-preço

As elasticidades-preço Hicksianas (ou compensadas) foram estimadas a partir das equações de Slutsky na forma de elasticidade:

$e_{i j}=h_{i j}+w_{j} h_{i x}{ }^{\prime \prime} i, j$
Marshallianas para a carne bovina e de frango de $-0,271$ e $-0,332$. Fernandes et al. (1989) estimaram elasticidades Marshallianas com relação aos próprios preços das carnes bovina, suína e de frango de -0,29, -0,76 e -0,19. Bacchi e Barros (1992) estimaram elasticidades de curto e longo prazo para a demanda por carne bovina com relação ao próprio preço em -0,51 e $-1,09$. Mais recentemente, Resende Filho et al. (2012), para o período de 1975 a 2008, estimaram elasticidades próprio-preço Marshallianas das carnes bovina $(-0,159)$, suína $(-0,053)$ e de frango $(-0,470)$ e também para os outros bens de consumo $(-1,018)$. Apesar de esses resultados não serem diretamente comparáveis 
aos do presente estudo, percebe-se que as suas magnitudes indicam que as estimativas obtidas no presente artigo são plausíveis.

Pela Tabela 6, nota-se que todos os bens apresentam elasticidades preços-cruzados Marshallianas, em módulo, inferiores às elasticidades próprio-preço, o que, como esperado, indica que a demanda deve ser mais sensível ao próprio preço do que aos preços dos bens correlatos. Observa-se, ainda, que todas as elasticidades preços-cruzados das carnes são positivas, confirmando que as carnes bovina, suína e de frango são bens substitutos brutos uns dos outros. Além disso, observa-se que a demanda por carne suína $(0,562>0,100)$ e por carne de frango $(0,456>$ $0,133)$ são mais sensíveis a variações no preço da carne bovina do que o contrário; e a demanda por carne suína é mais sensível a variações nos preços da carne de frango $(0,190>0,120)$ do que o contrário. Sendo assim, em termos de sensibilidade às variações nos preços das demais carnes, temos que a demanda por carne suína é mais sensível que a demanda por carne de frango que é mais sensível que a demanda por carne bovina.

As elasticidades preço-cruzado Marshallianas para cada tipo de carne com relação aos outros bens de consumo indicam que aumentos nos preços dos outros bens de consumo aumentam a demanda por carnes (Tabela 6). Já as elasticidades preços-cruzados Marshallianas dos outros bens de consumo com relação a cada carne são negativas, indicando que aumentos nos preços das carnes reduzem a demanda dos outros bens de consumo.

As elasticidades próprio-preço Hicksianas são todas negativas (vide sexta coluna da Tabela 6), como requerido pela teoria do consumidor ${ }^{26}$, e indicam que as demandas compensadas são inelásticas aos próprios preços. As elasticidades preços-cruzados Hicksianas mostram que as carnes

26. A diagonal principal da matriz de substituição de HicksSlutsky deve ser composta por números não positivos como uma das condições para que seja semidefinida negativa, ou equivalentemente, para que a função gasto seja côncava (proposição 3.G.3 em Mas-Colell et al., 1996). bovina, suína e de frango são substitutos líquidos uns dos outros.

Finalmente, as elasticidades-gasto na Tabela 6 revelam que outros bens de consumo é um bem de luxo $\left(\eta_{o x}=1,068\right)$; as carnes bovina, suína e de frango são necessidades $\left(\eta_{k x}<1\right.$ para todo $k=b, p$ e $c$ ), sendo a carne suína um bem inferior $\left(\eta_{p x}=-0,158\right)$ e as carnes bovina e de frango, bens normais. Com base nas elasticidades-gasto, um aumento do gasto (ou aproximadamente da renda) per capita acarreta, ceteris paribus, maior aumento na demanda de outros bens de consumo $(1,068)$ que na demanda por carne bovina $(0,163)$; maior aumento na demanda por carne bovina que na demanda por carne de frango $(0,055$, mas não estatisticamente significativa a $5 \%$ ); e redução na demanda por carne suína. Assim, como é provável o aumento do gasto per capita com consumo (ou aproximadamente da renda) no tempo, cetris paribus, o consumo de carnes deve perder importância para o de outros bens de consumo, o que confirma a lei de Engel para alimentos.

\section{Sumário e conclusões}

O presente estudo testou ao nível do mercado varejista nacional se informações sobre crises de segurança do alimento - mensurada com base em índices de notícias - causam deslocamentos para baixo nas demandas pelas carnes bovina, suína e de frango no varejo.

Com base nos índices de segurança do alimento para cada tipo de carne, os quais são o resultado da soma das notícias da Folha de São Paulo que atendem a critérios pré-definidos, detectaram-se seis grandes crises de segurança do alimento associadas a carnes: a primeira crise ocorre com um surto de peste suína nos rebanhos brasileiros em junho e julho de 1978; a segunda, em 1988, decorreu de um episódio de carne bovina importada contaminada com radiação; a terceira, em 1996, não apresentou uma razão, apesar de ter sido fortemente influenciada por notícias sobre potenciais casos de vaca louca na Europa; a quarta crise, entre janeiro e março de 
2003, está associada a notícias sobre o primeiro caso de BSE no Canadá; a quinta crise ocorre nos três primeiros meses de 2006 devido à gripe aviária; e finalmente, a sexta crise ocorre entre julho e outubro de 2009 devido a notícias sobre gripe suína. No entanto, o número médio de notícias da Folha de São Paulo sobre problemas de segurança do alimento para carnes foi muito pequeno, entre 1,027 e 1,865 notícia por ano.

Os gráficos das séries de preços indicaram tendências de aumento do consumo aparente per capita de cada tipo de carne, apesar de suas magnitudes serem diferentes segundo o tipo de carne. Observou-se ainda que o consumo de carne de frango no Brasil ultrapassou o consumo de carne suína a partir de 1979 e que o consumo aparente de carne de frango ultrapassou o consumo aparente de carne bovina no Brasil a partir de 2007.

A literatura recente consultada indica ser relevante trabalhar, como no presente estudo, com dados de consumo agregado (TONSOR et al., 2010; GLYNN e OLYNK, 2010); que há uma vasta e crescente literatura internacional devotada à estimação de sistemas de equações de demanda por carnes utilizando dados agregados de séries de tempo sem representantes recentes na literatura nacional; que é fundamental incluir em modelos de demanda por alimentos, além dos preços e renda do consumidor, variáveis relacionadas ao nível de confiança do consumidor com relação ao alimento que consome, em especial, com a inclusão de algum índice de notícias sobre crises de segurança do alimento em jornais ou com os recalls de alimentos. Sendo assim, o presente trabalho estimou sistema de equações de demanda por carnes no Brasil, incluindo índices anuais de segurança do alimento e para dados agregados de consumo para o período de 1975 a 2011.

Na estimação dos sistemas de equações de demanda para as carnes bovina, suína e de frango, incorporou-se preços e renda e, nas equações dos deslocadores dos interceptos das equações do modelo AIDS, séries de número de notícias sobre segurança do alimento para cada tipo de carne, variável tendência e uma variável binária para o Plano Real. Detectou-se que o Plano Real não afetou as demandas por carnes e outros bens de consumo e que houve mudanças estruturais nas demandas no sentido do aumento do consumo de carnes no Brasil.

Não foi possível rejeitar a hipótese de que os efeitos dos índices de segurança do alimento são conjuntamente zero e, portanto, conclui-se que se deslocamentos da demanda para baixo em reação a crises de segurança do alimento criam incentivos para que empresas adotem medidas para produzir um alimento mais seguro, tais incentivos não existem nos setores das carnes bovina, suína e de frango no Brasil. Com base nisso, fica evidenciada a importância e necessidade de um sistema público de regulamentação e regulação atuante. Ou seja, é fundamental existir políticas públicas que garantam e estabeleçam um sistema público de regulamentação e regulação vigilante, eficiente e atuante para o setor de carnes no Brasil. Para tanto, é importante ampliar o sistema de fiscalização, monitoramento, controle e autuação das empresas da cadeia produtiva das carnes bovina, suína e de frango no Brasil até o varejo. Também é importante criar incentivos para que os agentes ${ }^{27}$ do sistema público de regulamentação e regulação de carnes no Brasil desenvolvam

27. O Ministério da Agricultura, Pecuária e Abastecimento (Mapa) responde pelas fiscalizações oficiais em indústrias de produtos de origem animal e vegetal, fiscalizando os lotes dos produtos das empresas que solicitam o SIF (Sistema de Inspeção Federal), mas cabendo à empresa garantir a qualidade, conforme as normas previstas na lei. Nos abatedouros, uma equipe do Mapa e técnicos contratados pela própria empresa inspeciona cada animal morto (FREITAS, 2016). A Agência Nacional de Vigilância Sanitária (Anvisa) coordena e regulamenta as ações do Sistema Nacional de Vigilância Sanitária, do qual faz parte ainda as vigilâncias sanitárias de estados e municípios, as quais têm autonomia administrativa, e os laboratórios públicos de análises dos estados. A Anvisa regulamenta o que vai ser liberado para o comércio e uso pelas empresas, mas as indústrias são fiscalizadas pelos estados e os estabelecimentos comerciais, como bares, restaurantes e supermercados, pelas vigilâncias municipais. Tanto a Anvisa quanto as vigilâncias sanitárias têm autoridade para interditar, apreender produtos e multar estabelecimentos, mas quando algum problema é identificado pelo sistema nacional de vigilância sanitária, é a Anvisa quem adota medidas para reduzir o risco associado ao produto, como a suspensão deste, a determinação de seu recolhimento ou a proposta de novas regras de regulação (FREITAS, 2016). 
campanhas de sensibilização e conscientização dos consumidores e empresas quanto a questóes de segurança do alimento.

Vale dizer que os estudos que detectaram impactos negativos - apesar de impactos pequenos - das notícias sobre crises de segurança do alimento na demanda por carnes nos EUA utilizaram dados trimestrais (PIGGOTT e MARSH, 2004; RESENDE FILHO e BUHR, 2011; TONSOR et al., 2010; GLYNN e OLYNK, 2010). Contudo, não foram encontradas séries mensais ou trimestrais disponíveis de todas as variáveis necessárias a um estudo como o aqui apresentado. Sendo assim, sugere-se que em futuros trabalhos se tente viabilizar a coleta e, assim, a utilização de dados mensais ou, pelo menos, trimestrais.

As estimativas das elasticidades próprio-preço indicam que as demandas pelas carnes bovina, suína e de frango são inelásticas e elasticidades preços-cruzados confirmam que as carnes são bens substitutos brutos e líquidos umas das outras; já as estimativas das elasticidades-gasto indicam que todos os bens são normais, exceto a carne suína que é um bem inferior. Ademais, as elasticidades-gasto indicam que se o gasto das famílias brasileiras com consumo crescer, ceteris paribus, o consumo de carnes perderá importância para o consumo dos outros bens de consumo, confirmando a lei de Engel para alimentos. Finalmente, a plausibilidade das estimativas das elasticidades da demanda dá fortes indícios de robustez dos resultados obtidos no presente trabalho.

\section{Referências bibliográficas}

ALVES, R. Vigilância epidemiológica das doenças transmitidas por alimentos - VE-DTA. Palestra proferida no $3^{\mathfrak{o}}$ Encovisas - Encontro Nacional de Vigilâncias Sanitárias. São Paulo, SP, em 07 de agosto de 2014. Disponível em: <http://www.anrbrasil.org.br/new/ pdfs/2014/3_PAINEL_1_ApresentacaoRejaneAlvesV igilanciaEpidemiologica-VE-DTA-Agosto_2014_PDF. pdf>. Acesso em: 25 mar. 2016.

BACCHI, M. R. P. e BARROS, G. S. C. Demanda de carne bovina no mercado brasileiro. Revista de Economia e Sociologia Rural, v. 30, n. 1, p. 83-96, 1992.
BARNETT, W. A. Maximum likelihood and iterated Aitken estimation of nonlinear systems of equations. Journal of the American Statistical Association, v. 71, n. 354, p. 354-360, 1976.

. e SERLETIS, A. Consumer preferences and demand systems. Journal of Econometrics, v. 147, n. 2, p. 210-224, 2008.

BEHRENS, J. H. et al. Consumer purchase habits and views on food safety: a Brazilian study. Food Control, v. 21, n. 7, p. 963-969, 2010.

BERNDT, E. R. e SAVIN, N. E. Evaluation and hypothesis testing in singular equation systems with autoregressive disturbances. Econometrica, v. 32, n. 5/6, p. 937-957, 1975.

BOLETIM ELETRÔNICO EPIDEMIOLÓGICO. Doenças Transmitidas por Alimentos (DTA). Brasília, DF: Ministério da Saúde, Secretaria de Vigilância em Saúde, Ano 5, n. 06, 28 dez. 2005.

BRESTER, G. W. e SCHROEDER, T. C. The impacts of brand and generic advertising on meat demand. American Journal of Agricultural Economics, v. 77, n. 4, p. 969-979, 1995.

BURTON, M., YOUNG, T. e CROMB, R. Meat consumers' long-term response to perceived risks associated with BSE in Great Britain. Cahiers D'économie et Sociologie Rurales, v. 50, p. 7-19, 1999.

CARTER, C. A. e SMITH, A. The market effect of a food scare: the case of genetically modified Starlink corn. The Review of Economics and Statistics, v. 89, n. 3, p. 522533, 2007.

DEATON, A. e MUELLBAUER, J. An almost ideal demand system. American Economic Review, v. 70, n. 3, p. 312-326, 1980.

DICKEY, D. A. e FULLER, W. A. Likelihood ratio statistics for autoregressive time series with a unit root. Econometrica, v. 49, n. 4, p. 1057-72, 1981.

ENGLE, R. F. e GRANGER, C. W. J. Cointegration and error correction: representation, estimation and testing. Econometrica, v. 55, n. 2, p. 251-276, 1987.

FERNANDES, S. A., PANIAGO, E. e LIMA, J. E. Análises de políticas relacionadas com a demanda e a oferta de carnes no Brasil. Revista de Economia e Sociologia Rural, v. 27 , n. 4 , p. $556-561,1989$.

FISHER, D., FLEISSIG, A. R. e SERLETIS, A. An Empirical Comparison of Flexible Demand System Functional Forms. Journal of Applied Econometrics, v. 16, n. 16, p. $59-80,2001$. 
FOLHA DE SÃO PAULO. acervo FOLHA. Disponível em: <http://acervo.folha.com.br/busca_detalhada $>$. Acesso em: 2012.

FONSECA, M. C. P. Opinião dos consumidores sobre os riscos alimentares à saúde: o caso da carne bovina. 2004 . 251 f. Tese (Doutorado em Alimentos e Nutrição) Departamento de Alimentos e Nutrição, Universidade Estadual de Campinas, Campinas, 2004.

FREITAS, A. Quem fiscaliza o quê na cadeia de produção de alimentos. O Globo, Rio de Janeiro, 06 de junho de 2013, atualizado em 07 de maio de 2014. Economia, Defesa do Consumidor. Disponível em: < http://oglobo. globo.com/economia/defesa-do-consumidor/quemfiscaliza-que-na-cadeia-de-producao-de-alimentos8605592\#ixzz44r693yDS>. Acesso em: 04 abr. 2016.

GLYNN, T. e OLYNK, N. Impacts of animal wellbeing and welfare media on meat demand. Journal of Agricultural Economics, v. 62, n. 1, p. 59-72, 2011.

GREENE, W. H. Econometric analysis. New Jersey: Prentice Hall, 2003.

HENSON, S. e TRAILL, B. The demand for food safety: market imperfections and the role of government. Food Policy, v. 18, n. 2, p. 152-162, 1993.

INSTITUTO DE ECONOMIA AGRÍCOLA (IEA). Preços Médios Mensais no Varejo. Disponível em: <http://ciagri. iea.sp.gov.br/bancoiea/Precos_Medios.aspx?cod_ sis $=4>$. Acesso em: 2012.

INSTITUTO DE PESQUISA EM ECONOMIA APLICADA (IPEA). Banco de Dados do Instituto de Pesquisa em Economia Aplicada (IPEADATA). Disponível em: < http://www.ipeadata.gov.br/>. Acesso em: dez. 2012.

ITALIANER, A. A small-sample correction for the likelihood ratio test. Economics Letters, v. 19, n. 4, p. 31517, 1975.

JONGE, J. et al. Consumer confidence in the safety of food and newspaper coverage of food safety issues: a longitudinal perspective. Risk Analysis, v. 30, n. 1, p. 125-142, 2010.

KEUZENKAMP, H. A. e BARTEN, A. P. Rejection without falsification: on the history of testing the homogeneity condition in the theory of consumer demand. Journal of Econometrics, v. 67, n. 1, p. 103-127, 1995.

LEWBEL, A. e NG, S. Demand systems with nonstationary prices. Review of Economics and Statistics, v. 87, n. 3, p. 479-494, 2005.

MACKINNON, J. G. Numerical distribution functions for unit root and cointegration tests. Journal of Applied Econometrics, v. 11, n. 6, p. 601-18, 1996.
MARSH, T. L., SCHROEDER, T. D. e MINTERT, J. Impacts of meat product recalls on consumer demand in the USA. Applied Economics, v. 36, n. 9, p. 897-909, 2004.

MARUCHECK, A. et al. Product safety and security in the global supply chain: issues, challenges and research opportunities. Journal of Operations Management, v. 29, n. 7-8, 707-720, 2011.

MAS-COLEL, A., WHINSTON, M. D. e GREEN, J. R. Microeconomic Theory, Oxford University Press, 1995.

MAZZOCCHI, M., STEFANI, G. e HENSON, S. J. Consumer welfare and the loss induced by withholding information: the case of BSE in Italy. Journal of Agricultural Economics, v. 55, n. 1, p. 41-58, 2004.

MOSCHINI, G., MORO, D. e GREEN, R. Maintaining and testing separability in demand system. American Journal of Agricultural Economics, v. 76, n. 1, p. 61-73, 1994.

PHILLIPS, P. C. B. Time series regression with a unit root. Econometrica, v. 55, n. 2, p. 277-301, 1987.

. e PERRON, P. Testing for a unit root in time series regression. Biometrika, v. 75, n. 2, p. 335-46, 1988.

PHLIPS, L. Applied consumption analysis. NorthHolland, Amsterdam, 1974.

PIGGOTT, N. E. et al. Demand response to advertising in the Australian meat industry. American Journal of Agricultural Economics, v. 78, n. 2, p. 268-279, 1996.

. e MARSH, T. L. Does food safety information impact U.S. meat demand? American Journal of Agricultural Economics, v. 86, n. 1, p. 154-74, 2004.

POULIOT, S. e SUMNER, D. A. Traceability, recalls, industry reputation and product safety. European Review of Agricultural Economics, v. 40, n. 1, p. 121-142, 2013.

QUANTITATIVE MICRO SOFTWARE. EViews 7 command and programming reference. Irvine, USA: Quantitative Micro Software, 2010.

RESENDE FILHO, M. de A. Potenciais benefícios do sistema de rastreabilidade animal dos EUA para o setor de carnes americano. Revista de Economia e Sociologia Rural, v. 46, n. 4, p. 1129-1154, 2008.

e BUHR, B.L. Evidence of consumers' willingness to pay for the national animal identification system of the United States. Economia Aplicada, v. 15, n. 1., p. 5-22, 2011.

. et al. Sistemas de equações de demanda por carnes no Brasil: especificação e estimação. Revista de Economia e Sociologia Rural, v. 50, n. 1, p. 33-50, 2012. 
ROSS, T. e SUMNER, J. A simple, spreadsheet-based, food safety risk assessment tool. International Journal of Food Microbiology, v. 77, n. 1-2, p. 39-53, 2002.

SANTANA, A. C. Mudanças recentes nas relações de demanda de carne no Brasil. Revista de Economia e Sociologia Rural, v. 37, n. 2, p. 51-76, 1999.

SCHARFF, R. L. Economic burden from health losses due to foodborne illness in the united states. Journal of Food Protection, v. 75, n. 1, p. 123-131, 2012.

SCHROEDER, T. C., MARSH, T. L. e MINTERT, J. Beef demand determinants. Relatório preparado para the National Cattlemen's Beef Association, 2000. Disponível em: < < <ttp://www.agecon.ksu.edu/livestock/ Extension \%20Bulletins/BeefDemandDeterminants. pdf $>$.

SPERS, E. E. Mecanismos de regulação da qualidade e segurança em alimentos. 2004. 155 f. Tese (Doutorado em Administração) - Faculdade de Economia,
Administração e Contabilidade, Universidade de São Paulo, São Paulo, 2004.

TAVARES, T. M. e SERAFINI, A. B. Carnes de hambúrgueres prontas para consumo: aspectos legais e riscos bacterianos. Revista de Patologia Tropical, v. 35, n. 1, p. 1-21, 2006.

TONSOR, G., MINTERT, J. e SCHROEDER, T. U. S. Meat demand: household dynamics and media information impacts. Journal of Agricultural and Resource Economics, v. 35, n. 1, p. 1-17, 2010.

UNITED STATES DEPARTMENT OF AGRICULTURE, FOREIGN AGRICULTURAL SERVICE (USDA/FAS). Production, Supply and Demand Online: downloadable data sets. Disponível em: <http://www.fas.usda.gov/ psdonline/psdDownload.aspx>. Acesso em: dez. 2012.

VERBEKE, W. e WARD, R. W. A fresh meat almost ideal demand system incorporating negative tv press and advertising impact. Agricultural Economics, v. 25, n. 2-3, p. 359-374, 2001. 